\title{
Effects of Different Lipophilized Ferulate Esters in Fish Oil-Enriched Milk: Partitioning, Interaction, Protein, and Lipid Oxidation
}

Qiu, Xujian; Jacobsen, Charlotte; Villeneuve, Pierre; Durand, Erwann; Sørensen, Ann-Dorit Moltke

Published in:

Journal of Agricultural and Food Chemistry

Link to article, DOI:

10.1021/acs.jafc.7b02994

Publication date:

2017

Document Version

Peer reviewed version

Link back to DTU Orbit

Citation (APA):

Qiu, X., Jacobsen, C., Villeneuve, P., Durand, E., \& Sørensen, A-D. M. (2017). Effects of Different Lipophilized Ferulate Esters in Fish Oil-Enriched Milk: Partitioning, Interaction, Protein, and Lipid Oxidation. Journal of Agricultural and Food Chemistry, 65(43), 9496-9505. https://doi.org/10.1021/acs.jafc.7b02994

\section{General rights}

Copyright and moral rights for the publications made accessible in the public portal are retained by the authors and/or other copyright owners and it is a condition of accessing publications that users recognise and abide by the legal requirements associated with these rights.

- Users may download and print one copy of any publication from the public portal for the purpose of private study or research.

- You may not further distribute the material or use it for any profit-making activity or commercial gain

- You may freely distribute the URL identifying the publication in the public portal 
This document is confidential and is proprietary to the American Chemical Society and its authors. Do not copy or disclose without written permission. If you have received this item in error, notify the sender and delete all copies.

\section{Effects of different lipophilized ferulate esters in fish oil enriched milk: Partitioning, Interaction, Protein and Lipid Oxidation}

\begin{tabular}{|r|l|}
\hline Journal: & Journal of Agricultural and Food Chemistry \\
\hline Manuscript ID & jf-2017-02994x.R1 \\
\hline Manuscript Type: & Article \\
\hline Date Submitted by the Author: & n/a \\
\hline Complete List of Authors: & $\begin{array}{l}\text { Qiu, xujian; Jimei University, Food science } \\
\text { Jacobsen, Charlotte; Technical University of Denmark, National food } \\
\text { Institute } \\
\text { Villeneuve, Pierre; CIRAD } \\
\text { DURAND, Erwann; CIRAD, IATE } \\
\text { Sørensen, Ann-Dorit; Technical University of Denmark, National Food In } \\
\text { stitute, Division of Industrial Food Research }\end{array}$ \\
\hline
\end{tabular}

SCHOLARONE

Manuscripts 


\section{Effects of different lipophilized ferulate esters in fish oil enriched milk:}

\section{Partitioning, Interaction, Protein and Lipid Oxidation}

Xujian Qiu ${ }^{1,2}$, Charlotte Jacobsen ${ }^{2}$, Pierre Villeneuve ${ }^{3}$, Erwann Durand ${ }^{3}$ and Ann-Dorit Moltke Sørensen $^{2, *}$

${ }^{1}$ College of Food and Biological Engineering, Xiamen Key Laboratory of Marine Functional Food, Jimei University, 43 Yindou Road, Xiamen 361021, Fujian, China

${ }^{2}$ Division of Food Technology, National Food Institute (DTU Food), Technical University of Denmark, DK 2800 Kgs Lyngby, Denmark

${ }^{3}$ CIRAD, UMR IATE, Montpellier, F-34398, France

*Tel: +45 45252591. E-mail: adms@food.dut.dk 
1 ABSTRACT: Antioxidant effects of ferulic acid and lipophilized ferulate esters were investigated 2 in fish oil enriched milk. Methyl ferulate (C1) and ethyl ferulate (C2) more efficiently prevented 3 lipid oxidation than dodecyl ferulate (C12), followed by ferulic acid (C0). The combination of $\mathrm{C} 1$ 4 or C2 with C12 could have a "synergistic" effect indicated by peroxide value, hexanal, and 15 penten-3-ol analysis results. These antioxidants also showed protein oxidation inhibition effects. 6 The most effective antioxidants $(\mathrm{C} 1$ and $\mathrm{C} 2)$ had the highest concentration in the precipitate phase, 7 but lowest concentration in aqueous phase which was opposite to the partitioning of $\mathrm{C} 0 . \mathrm{C} 12 \mathrm{had}$ 8 the highest concentration in the oil and emulsion phase. In particular, the interaction between 9 ferulates esterified with short and medium alkyl chain lengths respectively could lead to their 10 "synergistic" effects in fish oil enriched milk, which could be caused by the change of their 11 partitioning or localization at the interface.

12 KEY WORDS: Ferulic acid, Ferulate ester, omega-3 PUFA, protein oxidation, lipid oxidation, 13 antioxidants, antioxidant partitioning, phenolipids 


\section{INTRODUCTION}

Fish oils are reported to have many health beneficial effects including reduced risk of cardiovascular and inflammatory diseases. This is attributed to the presence of long chain $n-3$ polyunsaturated fatty acids (PUFAs). ${ }^{1,2}$ It is thus of great interest to the food industry to enrich food with fish oil. However, fish oils that contain n-3 PUFA like eicosapentaenoic acid (EPA, 20:5) and docosahexanoic acid (DHA, 22:6) are highly prone to lipid oxidation. Lipid oxidation can cause development of compounds with an unpleasant off flavor in the product even at low concentrations (e.g. $1 \mu \mathrm{g} / \mathrm{kg}$ ). Moreover, lipid oxidation may also generate some oxidized compounds, which are potentially harmful to human health. ${ }^{3-5}$ Therefore, the use of efficient antioxidants in food is required to limit oxidation of the healthy n-3 PUFAs and other compounds in the food product.

Currently, there is an increasing interest in using natural antioxidants such as phenolic acids in foods. However, phenolic acids could have limited effectiveness in oil-in-water $(\mathrm{O} / \mathrm{W})$ emulsions since they are generally hydrophilic and have relatively high polarity. Polar antioxidants are less efficient in $\mathrm{O} / \mathrm{W}$ emulsions than apolar antioxidants according to the "polar paradox" theory put forwarded first by Porter $^{6}$ and Porter et al. ${ }^{7}$ This was explained by the partitioning of the antioxidants into the different phases. Apolar antioxidants were closely located to the interface, where lipid oxidation is initiated, whereas polar antioxidants are mainly located in the aqueous phase. The polarity/hydrophilicity of phenolic acids has therefore been modified by esterification with fatty alcohols in order to change the partitioning of the antioxidant in the $\mathrm{O} / \mathrm{W}$ emulsion system to get better antioxidant effects. ${ }^{8}$ Interestingly, the lipophilized phenolic acids have a higher antioxidant activity in $\mathrm{O} / \mathrm{W}$ emulsions with the increment of alkyl chain length but only to a certain limit termed critical chain length. With further increment of the chain length, the antioxidant effect was significantly decreased. Based on these results, the cut-off effect was introduced. ${ }^{9}$ The 
mechanism of the cut-off phenomenon is still not very clear despite the fact that there has been significant progress in this area recently. ${ }^{10}$

In particular, there are only a few studies on antioxidant efficacies of lipophilized phenolic acids in real food systems. A study on antioxidant effects of lipophilized caffeic acid has shown that methyl and butyl caffeates were most efficient in milk, whereas butyl, octyl and dodecyl caffeates were most efficient in mayonnaise, suggesting that the critical chain lengths of lipophilized phenolic compounds were different in different foods enriched with fish oil. ${ }^{11}$ Moreover, a study on dihydrocaffeates and rutin esters in fish oil enriched milk showed that phenolipids with medium chain were more efficient although phenolipids with only two different alkyl chain lengths were evaluated. ${ }^{12}$ In another study with lipophilized ferulic acid, methyl ferulate had the best antioxidant activity of all the ferulates and ferulic acid evaluated in fish oil enriched milk. Octyl and dodecyl ferulates were the least efficient compounds evaluated in this study where they acted as prooxidants in spite of their more apolar character than methyl ferulate. ${ }^{13}$

It is known that a combination of antioxidants can often provide synergistic antioxidant efficiency although the mechanism is not completely understood. To the best of our knowledge, there have been no studies performed on a combination of antioxidants of lipophilized ferulic acids with different alkyl chain lengths. Therefore, it is of interest to test the antioxidant efficiency of the mixed lipophilized ferulic acids. Based on former experiment with fish oil enriched milk ${ }^{13}$, the combination of ferulate esters with short alkyl chain length and medium alkyl chain length was selected. In addition, only few studies have evaluated the partitioning of antioxidants in fish oil enriched milk as well as the effect of phenolipids on protein oxidation. Thus, the first aim of this study was to evaluate the effects of ferulic acid, ferulate esters, and a combination of short and medium alkyl chain ferulate esters on the oxidative stability of fish oil enriched milk. Both lipid and 
60 protein oxidation was assessed. The second aim was to compare the oxidative stability to the

61 partitioning of ferulic acid and ferulates in fish oil enriched milk.

\section{MATERIALS AND METHODS}

Materials. Pasteurized milk with $0.4 \%$ and $1.5 \%$ fat content was purchased from a local supermarket. Cod liver fish oil was supplied by Maritex A/S (TINE BA, Sortland, Norway). The peroxide value (PV) of the fish oil was $0.65 \mathrm{meq}$ peroxides $/ \mathrm{kg}$. The fish oil had $242 \mathrm{mg}$ atocopherol/kg, $119 \mathrm{mg} \gamma$-tocopherol $/ \mathrm{kg}, 44 \mathrm{mg} \delta$-tocopherol $/ \mathrm{kg}$, respectively. The fatty acid composition of the oil was analyzed by GC as: C14:0, 3.8\%; C16:0, 9.9\%; C16:1 (n-7), 9.4\%; C18:0, 2.0\%; C18:1 (n-9), 17.2\%; C18:1 (n-7), 4.8\%; C18:2 (n-6), 2.0\%; C18:3 (n-3), 2.8\%; C18:4(n-3), 0.2\%; C20:1, 13.2\%; C20:5 (n-3) (EPA), 9.8\%; C22:1(n-11), 5.8\%; C22:5(n-3),1.2\%;C 22:6 (n-3) (DHA), 11.9\% (w/w).

Methyl (C1) and dodecyl (C12) ferulates used in the study were synthesized by the grafting respective alcohols to ferulic acid according to the procedure described by Sørensen et al. ${ }^{14}$ Ferulic acid (C0) and ethyl ferulate (C2) were purchased from Sigma-Aldrich (Steinheim, Germany). All solvents used were of HPLC grade and purchased from Lab-Scan (Dublin, Ireland). Standards for quantification of volatile lipid oxidation products were from Sigma-Aldrich (Steinheim, Germany).

Production of fish oil enriched milk with different antioxidants. Milk with $1.5 \%$ and $0.4 \%$ fat content were mixed $(6: 5, \mathrm{w} / \mathrm{w})$ to obtain a total fat content of $1 \%$. Milk was then heated to $72{ }^{\circ} \mathrm{C}$ and kept for $15 \mathrm{sec}$. The selected temperature and time is known to get a better oxidative stability of the fish oil enriched milk according to a previous study. ${ }^{15}$ Fish oil $(0.5 \%$, w/w) was then added to the milk while stirring manually. The fish oil enriched milk was homogenized with a two-valve homogenizer (Rannie, Albertslund, Denmark) with a pressure of 225 bar and recirculated for 3 
82 times. To have enough fish oil enriched milk for all sample codes and sampling times, two batches 83 (3 $\mathrm{kg}$ each batch) were prepared and then pooled.

84 The fish oil enriched milk was then divided into $1000 \mathrm{ml}$ autoclaved bottles and the different 85 methanolic antioxidant solutions $(\mathrm{C} 0, \mathrm{C} 1, \mathrm{C} 2$ and $\mathrm{C} 12)$ were added to 4 bottles separately to make $86100 \mu \mathrm{M}$ final concentration. For the sample codes with combination of two ferulates, $\mathrm{C} 1(50 \mu \mathrm{M})$ or $87 \mathrm{C} 2(50 \mu \mathrm{M})$ was combined with $\mathrm{C} 12(50 \mu \mathrm{M})$ i.e. total antioxidant concentration $100 \mu \mathrm{M}$. For the control (Con), only methanol was added in same amount as the antioxidant solutions. After gently shaking, the bulk samples of the different emulsions were then divided into $100 \mathrm{~mL}$ sterilized bottles for storage at $5{ }^{\circ} \mathrm{C}$ in darkness. On day $0,3,6,9$ and 13 , one bottle of each code samples were taken out and divided into $50 \mathrm{ml}$ brownbottles, flushed with nitrogen and stored at $-40{ }^{\circ} \mathrm{C}$ for chemical analysis. On day 1 and day 13, droplet size of each sample code was measured without prior freezing of the samples. On day $1,100 \mathrm{~mL}$ of each treatment except Con was taken out to determine the partitioning of ferulic acid and ferulate esters in the fish oil enriched milk.

\section{Methods of Analysis}

Droplet size measurement. A few drops of the sample were suspended in recirculating distilled water (2800 rpm, obscuration 13-15\%, method: Fraunhofer) to measure the lipid droplet size in the fish oil enriched milk by a laser diffraction particle size analyzer (Mastersizer 2000, Malvern Instruments Ltd., Worcestershire, UK). Triplicate samples were measured. $\mathrm{D}_{3,2}$ was used to report the results.

Lipid extraction by Bligh and Dyer method. Lipid from fish oil enriched milk samples was extracted by Bligh and Dyer method. ${ }^{16}$ Briefly, milk sample was homogenized with methanol, chloroform and water $(1: 2: 2: 1, \mathrm{w} / \mathrm{v} / \mathrm{v} / \mathrm{v})$. After phase separation by centrifugation, the chloroform layer which 
104 contained lipid was kept for analysis. For each treatment, duplicate lipid extractions were performed 105 and analyzed for peroxide value (PV), fatty acid composition and tocopherols.

$P V$ analysis. Lipid extracts from the samples were evaporated to dryness under nitrogen. PV analysis was performed on the same day of lipid extraction based on a method described by Shantha and Decker. ${ }^{17}$ Results were reported as meq peroxides/kg lipids.

Fatty acid composition analysis. Lipid extracts were evaporated to dryness under nitrogen before 110 analysis. $100 \mu \mathrm{L}$ internal standard C23:0 in heptane, $200 \mu \mathrm{L}$ heptane with BHT and $100 \mu \mathrm{L}$ toluene 111 were added. Lipids were methylated with boron trifluoride reagent (20\%) by a one-step procedure 112 using a microwave (Multiwave 3000 SOLV, Anton Paar, Graz, Austria) with a 64MG5 rotor. 113 Samples were heated for $5 \mathrm{~min}$ at $500 \mathrm{~W}$ and cooled down for $10 \mathrm{~min}$. Then it was mixed with 1 $114 \mathrm{~mL}$ saturated $\mathrm{NaCl}$ solution and $0.7 \mathrm{~mL}$ heptane. The top layer was used for analysis by gas 115 chromatography with flame ionization detection (GC-FID) (HP 5890A, Agilent Technology, Palo 116 Alto, CA) according to AOCS official Method Ce $1 \mathrm{~b}-89 .{ }^{18}$ A DB-wax column $(10 \mathrm{~m} \times$ ID $0.1 \mathrm{~mm} \times$ $1170.1 \mu \mathrm{m}$ film thickness, J\&W Scientific, Folsom, CA) was used for analysis. The oven temperature 118 program was set initially as $160{ }^{\circ} \mathrm{C}$ and increased gradually to $200{ }^{\circ} \mathrm{C}$ at $10.6{ }^{\circ} \mathrm{C} / \mathrm{min}$, kept at $119200{ }^{\circ} \mathrm{C}$ for $0.3 \mathrm{~min}$, and increased to $220{ }^{\circ} \mathrm{C}$ at $10.6{ }^{\circ} \mathrm{C} / \mathrm{min}$, kept at $220{ }^{\circ} \mathrm{C}$ for $1 \mathrm{~min}$, then 120 increased to $240{ }^{\circ} \mathrm{C}$ at $10.6{ }^{\circ} \mathrm{C} / \mathrm{min}$ and finally kept at $240{ }^{\circ} \mathrm{C}$ for $3.8 \mathrm{~min}$. Injection volume is 0.2 $121 \mu \mathrm{L}$ with a split ratio of 1:50. Results were reported as percentages of total fatty acids.

122 Tocopherol concentration determination. Tocopherol concentration in samples were analyzed based 123 on the AOCS official method Ce $8-89 .{ }^{19}$ Briefly, lipid extracts were evaporated to dryness under 124 nitrogen and dissolved in $1 \mathrm{~mL}$ heptane and directly analyzed by HPLC (Agilent 1100 series, 125 Agilent Technology, Palo Alto, CA) with a fluorescence detector. The different tocopherols were 126 separated on a silica column (Waters, $4.6 \mathrm{~mm} \times 150 \mathrm{~mm}, 3 \mu \mathrm{m}$ ). The mobile phase was isopropanol 
127 in hexane $(0.5: 99.5, \mathrm{v} / \mathrm{v})$. The excitation wavelength and the emission wavelength were set at 290

$128 \mathrm{~nm}$ and $330 \mathrm{~nm}$ respectively. Results were reported as $\mu \mathrm{g}$ tocopherol/g lipid.

129

130

131

132

133

134

135

136

137

138

139

140

141

142

143

144

145

146

147

148

149

150

Volatile compound analysis. A dynamic headspace gas chromatography mass spectrometry (GC-

MS) method was used to analyze the volatile compounds of the milk samples. $4 \mathrm{~g}$ of milk samples with $0.5 \mathrm{~mL}$ of antifoam (Synperonic, $800 \mu \mathrm{L} / \mathrm{mL}$ water) was put in a pear shaped bottle and heated in a water bath at $45{ }^{\circ} \mathrm{C}$ for $30 \mathrm{~min}$. A nitrogen flow of approximately $150 \mathrm{~mL} / \mathrm{min}$ was used to purge the milk sample in order to release the volatile compounds from the milk into a Tenax GR packed tube. Tenax GR tubes were put in an automatic thermal desorber (ATD-400, Perkin Elmer, Waltham, MA) to desorb the volatiles. Volatile compounds were then transferred automatically from ATD to a GC (Agilent 6890, Palo Alto, CA) with a mass selective detector (HP 5973). A DB1701 column $(30 \mathrm{~m}, 0.25 \mathrm{~mm} \times 1 \mathrm{~mm}$ film thickness, J\&W Scientific, Folsom, CA) was used to separate the volatile compounds. The oven temperature was kept at $45{ }^{\circ} \mathrm{C}$ for $5 \mathrm{~min}$, increased to $55{ }^{\circ} \mathrm{C}$ at $1.5{ }^{\circ} \mathrm{C} / \mathrm{min}$, and increased from $55{ }^{\circ} \mathrm{C}$ to $90{ }^{\circ} \mathrm{C}$ at $2.5{ }^{\circ} \mathrm{C} / \mathrm{min}$, then increased to $220{ }^{\circ} \mathrm{C}$ at $12{ }^{\circ} \mathrm{C} / \mathrm{min}$ and finally kept at $220^{\circ} \mathrm{C}$ for $4 \mathrm{~min}$. Compounds were identified using the NIST data base and also confirmed with authentic standards. Volatile compounds in the samples were then quantified according to the external standard calibration curves using the ChemStation software. 30 $\mathrm{mg}$ of mixed external standard solutions ranged from $0.1 \mu \mathrm{g} / \mathrm{g}$ to $10 \mu \mathrm{g} / \mathrm{g}$ was added to $4 \mathrm{~g}$ fresh milk (1.5\% fat content) and also analyzed in the same way to prepare the calibration curves. Each sample was analyzed in triplicate and results were reported as ng volatile/g milk.

Protein carbonyls analysis. Protein oxidation in the milk samples was evaluated by carbonyl analysis based on the method by Levine et al. ${ }^{20}$ and Fenaille et al. ${ }^{21}$ Briefly, $50 \mu \mathrm{L}$ of milk was incubated with $0.5 \mathrm{~mL} 10 \mathrm{mM} \mathrm{DNPH}$ in $2 \mathrm{M} \mathrm{HCl}$ for $30 \mathrm{~min}$ in dark at room temperature. For the same milk sample a control was performed $(0.5 \mathrm{~mL} 2 \mathrm{M} \mathrm{HCl}$ without DNPH). Milk proteins were precipitated with $10 \%(\mathrm{w} / \mathrm{v})$ TCA (final concentration) and recovered by centrifugation. Protein 
151 pellets were washed 3 times with $1 \mathrm{~mL}$ of ethanol/ethyl acetate 50:50 (v/v) to completely remove

152 free DNPH reagent. The pellet was redissolved in $1 \mathrm{~mL}$ of $6 \mathrm{M}$ guanidine hydrochloride (pH 2.3).

153 Protein carbonyls and protein content were determined by UV at $370 \mathrm{~nm}$ and $280 \mathrm{~nm}$ respectively

154 using a spectrophotometer. An extinction coefficient of $2.2 \times 10^{4} \mathrm{M}^{-1} \mathrm{~cm}^{-1}$ was used for the

155 calculation of carbonyls. Results were expressed as nmol carbonyl/mg protein $(n=3)$.

156 Determination of the partitioning of ferulic acid and ferulates in fish oil enriched milk. A simple

157 ultracentrifuge procedure based on the method described by Jacobsen et al. with modification ${ }^{22}$ was

158 used to determine the partitioning of ferulic acid and ferulate esters in fish oil enriched milk

159 samples. Triplicate samples of $20 \mathrm{~mL}$ were ultracentrifuged (Beckman Coulter Inc., Palo Alto, CA)

160 for $2 \mathrm{~h}$ at $15^{\circ} \mathrm{C}$ at $110,000 \mathrm{~g}$. After centrifugation, samples were frozen at $-18{ }^{\circ} \mathrm{C}$ to facilitate the

161 separation of the obtained phases. There were 3 phases obtained after centrifugation: oil and

162 emulsion (containing milk fat globule membrane), aqueous, and precipitate. Oil and emulsion phase

163 was removed carefully by a sharp small spatula. Aqueous phase and precipitate could be poured out

164 from the centrifuge tubes directly. Each phase was weighed and diluted with ethanol (1:4) and

165 sonicated for $1 \mathrm{~min}$ except aqueous phase. Aqueous phase was directly filtered through a $0.45 \mu \mathrm{m}$

166 PVDF syringe filter and analyzed. The mixed solution was then centrifuged and the supernatant was

167 also filtered through the same type filter before HPLC analysis.

168 Ferulic acid and ferulate esters were determined by HPLC (Agilent 1100 series, Agilent Technology,

169 Palo Alto, CA) at $328 \mathrm{~nm}$ based on the method described by Guyot et al. ${ }^{23}$ with modification. An

170 ODS-3 column $(250 * 4.6 \mathrm{~mm}, 5 \mu \mathrm{m}$; Phenomenex, Torrance, CA) reversed phase column was used

171 for the determination for all the samples. Elution was obtained by using a mobile phase of solvents

172 A [water (pH 3)] and B [methanol/acetonitrile (1:1)]. Gradient elution was as follows: 95:5 (A/B)

173 for $2 \mathrm{~min}$ then to $60: 40(\mathrm{~A} / \mathrm{B})$ over $3 \mathrm{~min}$, to $0: 100(\mathrm{~A} / \mathrm{B})$ over $10 \mathrm{~min}$ and 0:100 (A/B) for $5 \mathrm{~min}$,

174 then reversion back to 95:5 (A/B) over $1 \mathrm{~min}$, finally 95:5 (A/B) for $4 \mathrm{~min}$. The flow rate was 0.9 
$175 \mathrm{~mL} / \mathrm{min}$. Standard solutions of ferulic acid and ferulates were analyzed under the same HPLC

176 conditions to identify and quantify the ferulic acid and ferulates in each sample prepared from

177 different phases.

178 Statistical Analysis. All data shown represent the mean value \pm standard deviation of duplicate or

179 triplicate measurements. Data from the different quality parameters were subjected to one-way 180 analysis of variance using SPSS software (version 19.0; SPSS Inc., Chicago, IL). Comparison of 181 means was performed using a least squares difference (LSD) method $(P<0.05)$. For PV or volatile 182 compound results, we use the term "synergistic" effect of $\mathrm{C} 1(\mathrm{C} 2)$ with $\mathrm{C} 12$ when there was no 183 statistical difference between $\mathrm{C} 1(\mathrm{C} 2)+\mathrm{C} 12$ and $\mathrm{C} 1(\mathrm{C} 2)$, but when the values of the combination 184 were significantly lower than $\mathrm{C} 12$. Only when $\mathrm{C} 1(\mathrm{C} 2)+\mathrm{C} 12$ showed statistical significance when 185 compared with $\mathrm{C} 1(\mathrm{C} 2)$ and $\mathrm{C} 12$, they were compared with the expected values to determine the 186 "synergistic" effects. For PV and volatile compound analysis results, expected C1(C2)+C12 were 187 calculated by the average of $\mathrm{C} 1(\mathrm{C} 2)$ with $\mathrm{C} 12$. This approach to evaluate synergistic effect is 188 somewhat different from the commonly used approach where a synergistic effect is considered 189 when the sum of the effects of individual compounds each added in a concentration of $\mathrm{x}$ and $\mathrm{y}$ is 190 lower than the effect of the two compounds added together in a concentration of $x+y$. The effect is 191 usually measured as \% inhibition of the measured parameters. To highlight that a different approach 192 has been used in this study the term synergistic is quoted.

\section{RESULTS AND DISCUSSION}

194 Droplet size of the lipid in milk emulsion system. Overall, the droplet size of the lipid in all the

195 samples increased from an average of $0.81 \mu \mathrm{m}$ to $0.87 \mu \mathrm{m}$ during the whole storage period (data not

196 shown). No creaming or flocculation was observed during 13 days of storage at $5{ }^{\circ} \mathrm{C}$. The lipid

197 droplet size of the fish oil enriched emulsion was slightly higher than in our previous studies. ${ }^{12,13}$ It 
may be related with the natural variation in the composition of milk used in the different studies. Particle size can range from 0.5 to $1.6 \mu \mathrm{m}$ in fish oil enriched milk samples depending on the homogenization temperature and pressure. ${ }^{24}$ Particle size can influence the oxidation stability of emulsion as reported by Let et al.15 This is not the focus of the present research and has been investigated before. Moreover, differences in droplet sizes were not significant and most likely did not affect lipid oxidation.

Fatty acid composition. EPA contents of all the samples on day 0 were from $3.54-3.70 \%$ and $3.41-3.74 \%$ on day 13 . DHA contents changed from $4.26-4.72 \%$ on day 0 to $4.13-4.45 \%$ on day 13 (data not shown). No significant reduction of EPA and DHA content was observed for samples between day 0 and day 13 except slight reduction for the C0 sample. EPA and DHA are prone to oxidation due to their highly unsaturated nature. In previous studies, the reduction could be significant or non-significant depending on the extent of lipid oxidation. ${ }^{11,12}$

Change of PV in fish oil enriched milk emulsions. In general, PV of the control sample increased dramatically from day 0 to day 6 and then maintained stable values (Figure 1). For both $\mathrm{C} 0$ and $\mathrm{C} 12$ samples, PV increased gradually from day 0 to day 9 at a rate of 0.98 and 0.77 meq peroxides $/ \mathrm{kg}$ lipid per day, respectively and then became steady. Control sample had significantly higher values than both $\mathrm{C} 0$ and $\mathrm{C} 12$ sample from day 3 till the end of the storage, while $\mathrm{C} 0$ had significantly higher PV than $\mathrm{C} 12$ after day $6(P<0.05) . \quad \mathrm{C} 1+\mathrm{C} 12$ and $\mathrm{C} 2+\mathrm{C} 12$ had very similar slightly increasing PVs during the whole storage period, in agreement with the very similar PVs of $\mathrm{C} 1$ and $\mathrm{C} 2$. From day 6 , the combination of $\mathrm{C} 1$ or $\mathrm{C} 2$ with $\mathrm{C} 12$ had significantly higher PVs than either $\mathrm{C} 1$ or $\mathrm{C} 2$, but lower PVs than $\mathrm{C} 12$ and the expected combination values indicated as dashed lines in Figure $1 \quad(P<0.05)$. The lower PVs than expected values based on the individual treatments indicated a "synergistic" effect of the combination of ferulates with short and medium chain lengths. Further studies are required to confirm this preliminary finding on the "synergistic" effect and 
synergistic effect with the use of other chain lengths or type of phenolipids. Furthermore, the 223 synergistic effect should be investigated at other concentrations than that applied in the present 224 study. C1 and C2 showed a very slight increase in PV throughout the storage period and had the 225 lowest PV compared to all other treatments. However, the low PV did not necessarily indicate low 226 lipid oxidation as the peroxides may be transformed into secondary oxidation products. The 227 secondary oxidation products results presented next could provide a better profile of the lipid 228 oxidation in all the treatments.

229 Change of volatile secondary oxidation products during storage. Secondary oxidation products 230 are mainly derived from the decomposition of primary lipid hydroperoxides. Hexanal, 1-penten-3231 one, 1-penten-3-ol, 2,4-heptadienal, 2-pentenal, 1-hexanol, 2,6-nonadienal were quantified. Figure 2 232 shows the changes of hexanal, 1-penten-3-one, 1-penten-3-ol and 2,4-heptadienal. They represent 233 the general development trend of the volatile secondary compounds quantified during storage. In 234 addition, 1-penten-3-one, 1-penten-3-ol, 2,4-heptadienal were found to be related to the off flavor generated by oxidation of n-3 PUFAs. ${ }^{25}$

236 Hexanal are mainly from the oxidation of n-6 fatty acids and is a very important index of lipid oxidation. Both fish oil and milk fat contain significant amount of n-6 fatty acids, which are easily oxidized due to the unsaturated nature. Hexanal in all the samples reached the peak on day 6 and then gradually decreased or remained constant in concentration (Figure 2). Corresponding to the PV results, all the treatment had much lower concentrations than the control sample while $\mathrm{C} 0$ and $\mathrm{C} 12$ 241 had much higher concentrations than all other ferulate treatments after day $3(P<0.05)$. These 242 results confirmed the strongest antioxidant effects of lipophilized ferulic acid with short alkyl chain 243 lengths. In addition, there was no significant difference between $\mathrm{C} 12$ and $\mathrm{C} 0$ with regard to PV until 244 day 9, however, C12 sample had significantly lower hexanal content than C0 sample starting from 245 day $6(P<0.05)$. This finding suggested that $\mathrm{C} 12$ and other shorter lipophilized ferulic acid could 
246 have stronger antioxidant effects by inhibiting not only primary oxidation but also the secondary 247 oxidation reactions compared to ferulic acid. This is particular important as the volatile compounds 248 due to oxidation could cause off flavor of the food products. On day 13, the ranking order of the 249 concentration of hexanal was: $\mathrm{Con}^{\mathrm{a}}>\mathrm{C} 0^{\mathrm{b}}>\mathrm{C} 12^{\mathrm{c}}>\mathrm{C} 1+\mathrm{C} 12^{\mathrm{d}}=\mathrm{C} 2+\mathrm{C} 12^{\mathrm{d}}=\mathrm{C} 1^{\mathrm{d}}=\mathrm{C} 2^{\mathrm{d}}$. The hexanal 250 concentration in $\mathrm{C} 1+\mathrm{C} 12$ or $\mathrm{C} 2+\mathrm{C} 12$ was not significantly higher than $\mathrm{C} 1$ or $\mathrm{C} 2$, but significantly 251 lower than $\mathrm{C} 12$, suggesting a "synergistic" effect of the combination of $\mathrm{C} 1$ or $\mathrm{C} 2$ with $\mathrm{C} 12$ on the 252 reduction of hexanal content.

253 The content of 1-penten-3-one in all the samples also reached a peak concentration on day 6 except 254 for C2 sample (Figure 3). In contrast to hexanal, 1-penten-3-one decreased sharply after day 6 and 255 reached to approximately the same level for all the treatments at the end of the storage. The decline 256 of 1-penten-3-one in fish oil enriched milk samples at later stage of storage period was also found in 257 other similar studies. ${ }^{4,11,13} \mathrm{C} 0$ and $\mathrm{C} 12$ did not show lower concentration of 1-penten-3-one 258 compared to the control until day 6 while the other treatments had significantly lower 1-penten-3259 one concentration compared to the control starting from day $3(P<0.05)$. The biggest difference in 260 1-penten-3-one concentrations among all treatments was shown on day 6. C2 had the lowest 1261 penten-3-one concentration among all the treatments $(P<0.05) . \mathrm{C} 1, \mathrm{C} 1+\mathrm{C} 12$ and $\mathrm{C} 2+\mathrm{C} 12$ showed 262 similar antioxidant effects $(P>0.05)$. The dramatic decline of 1-penten-3-one at the end of storage 263 period was probably related to its reaction with other components in the milk sample. ${ }^{11}$

264 1-penten-3-ol is developed during the decomposition of hydroperoxides of the n-3 polyunsaturated 265 fatty acids. ${ }^{26}$ In contrast to 1-penten-3-one, 1-penten-3-ol increased steadily during the whole 266 storage period after a lag phase of 3 days (Figure 4). Starting from day 6, the concentration of 1267 penten-3-ol in both $\mathrm{C} 2$ and $\mathrm{C} 1$ had more than 50\% reduction compared to the control. On day 13 , 268 the ranking order of the sample codes based on the concentration of 1-penten-3-ol was: $\operatorname{Con}^{\mathrm{a}}>$ $269 \mathrm{C} 0^{\mathrm{b}}=\mathrm{C} 12^{\mathrm{b}}>\mathrm{C} 1+\mathrm{C} 12^{\mathrm{c}}=\mathrm{C} 2+\mathrm{C} 12^{\mathrm{c}}>\mathrm{C} 1^{\mathrm{d}}=\mathrm{C} 2^{\mathrm{d}}$. Moreover, the concentration of 1-penten-3-ol in both 
$270 \mathrm{C} 1+\mathrm{C} 12$ and $\mathrm{C} 2+\mathrm{C} 12$ were lower than their expected values, respectively $(P<0.05)($ data not 271 shown), indicating a "synergistic" effect of the combination of $\mathrm{C} 1$ or C2 with $\mathrm{C} 12$.

272 Corresponding to the increase in PV, a dramatic increase in 2,4-heptadienal for Con and C0 samples 273 were observed after day 3 , while a much slower increase was observed in all the ferulate treatments 274 (Figure 5). At the end of storage, the ranking order of the sample codes based on the concentration 275 of 2,4-heptadienal was: $\mathrm{Con}^{\mathrm{a}}=\mathrm{C} 0^{\mathrm{a}}>\mathrm{C} 12^{\mathrm{b}} \geqslant \mathrm{C} 1+\mathrm{C} 12^{\mathrm{bc}}=\mathrm{C} 2+\mathrm{C} 12^{\mathrm{bc}} \geqslant \mathrm{C} 1^{\mathrm{c}}=\mathrm{C} 2^{\mathrm{c}}$. A "synergistic" effect 276 could not be determined due to the relatively high standard deviations.

Overall, for all the compounds quantified in the present study, $\mathrm{C} 2$ and $\mathrm{C} 1$ had the lowest concentration for all the volatile compounds followed by $\mathrm{C} 2+\mathrm{C} 12, \mathrm{C} 1+\mathrm{C} 12, \mathrm{C} 12$ and $\mathrm{C} 0$. Con had the highest concentration of the analyzed volatile compounds. This kind of difference was also observed in the PV results. These findings clearly demonstrated that lipophilization of ferulic acid with short alkyl chain lengths caused a dramatic increase of the antioxidant activity, but the antioxidant activity was sharply reduced with medium alkyl chain lengths in fish oil enriched milk. In addition, an indication of a "synergistic" antioxidant activity of ferulates with short and medium alkyl chain lengths were observed as shown in PV, hexanal and 1-penten-3-ol results.

Change of tocopherol in the fish oil enriched milk samples. Tocopherol of the milk samples mainly originated from the fish oil used in the study. The samples can be separated into three groups roughly based on the changing trend of a- tocopherol contents (Figure 6). During the whole storage period, $\mathrm{C} 1$ and $\mathrm{C} 2$ treatments had the lowest a-tocopherol reduction while a-tocopherol 289 levels in $\mathrm{C} 1+\mathrm{C} 12$ and $\mathrm{C} 2+\mathrm{C} 12$ were reduced moderately. $\mathrm{C} 0, \mathrm{C} 12$ and Con treatments had the 290 highest reduction. There were significant differences in the content of a-tocopherol among these 3 groups starting from day 6 except $\mathrm{C} 0$ sample on day $6(P<0.05)$. In general, it showed that changes 
2933 groups although there was some discrepancy within the highest reduction group (Con, C0, and 294 C12). These findings were also in agreement with previous studies by Alemán et al. ${ }^{11}$ and Sørensen 295 et al. ${ }^{12}$ There was not as high amount of $\gamma$-, $\delta$-tocopherol as a-tocopherol in the samples. The 296 reduction trend of $\gamma$ - tocopherol was not as significant as for a-tocopherol, and there was no obvious 297 trend in the change of $\delta$-tocopherol (data not shown).

298 Protein oxidation in fish oil enriched milk. Changes in protein carbonyls in various milk samples 299 are shown in Figure 7. Increase in carbonyls indicates protein oxidation during storage. ${ }^{27}$ The 300 amount of protein carbonyls in the control samples increased significantly during the storage from 301 day 0 to day $13(P<0.05)$, corresponding to the dramatic increase of PV (Figure 1). The 302 combination of $\mathrm{C} 1$ or $\mathrm{C} 2$ with $\mathrm{C} 12$ also showed inhibition effects for protein oxidation throughout 303 the storage. Although C12 showed stronger lipid oxidation inhibition effects than $\mathrm{C} 0$, this was not 304 the case for protein oxidation. C2 had the lowest carbonyls among all the treatments at the end of 305 the storage $(P<0.05)$.

306 The protein oxidation observed by increase of carbonyls could be caused by the lipid oxidation 307 products as these two reactions often occur simultaneously. Reactive oxygen species generated 308 from lipid oxidation process can react with protein and cause protein oxidation. ${ }^{28} \mathrm{C} 1$ and $\mathrm{C} 2$ 309 showed strong inhibition of lipid oxidation and consequently protein oxidation. The contrast in lipid 310 and protein oxidation results observed with $\mathrm{C} 12$ and $\mathrm{C} 0$ suggested that $\mathrm{C} 0$ could exhibit extra 311 protection of protein from oxidation other than by reducing the lipid oxidation products. This could 312 be related to the difference of hydrophobicity of $\mathrm{C} 12$ and $\mathrm{C} 0$ and thus their different partitioning in 313 the milk sample as presented below. Further research such as loss of sulphydryl content is needed to 314 confirm the effects of lipophilized ferulate esters on protein oxidation. In addition, research on 315 whether 1-pentent-3-one generated in the lipid oxidation process could react with protein could help 316 to understand the mechanism of protein oxidation. 
317 Partitioning of lipophilized ferulates in the fish oil enriched milk. Milk samples were physically

318 separated into 3 different phases after ultracentrifugation: oil and emulsion, aqueous, and precipitate.

319 The oil and emulsion phase was the top layer after ultracentrifugation and consisted of small

320 amounts of oil and milk fat globule membrane. It was difficult to completely separate the oil from

321 emulsion by the method used in this study, and this is the reason for the combination of them into

322 one phase. The precipitate phase contained proteins both from the aqueous phase and the $\mathrm{O} / \mathrm{W}$

323 interface layer. Approximately $61.9 \%$ of $\mathrm{C} 12$ partitioned in the oil and emulsion phase, followed by

$324 \mathrm{C} 2(50.8 \%)$ and $\mathrm{C} 1(40.3 \%)$, while $\mathrm{C} 0(13.2 \%)$ had the lowest percentage in this phase $(P<0.05)$

325 (Figure 8). This is in agreement with their corresponding hydrophobicity. In the aqueous phase, $\mathrm{C} 0$

326 had the highest percentage (70\%). Unexpectedly, C12 which is much more hydrophobic than either

$327 \mathrm{C} 1$ or $\mathrm{C} 2$ had higher percentage in the aqueous phase than $\mathrm{C} 1$ or $\mathrm{C} 2(P<0.05)$. However, this could

328 be explained as some of $\mathrm{C} 12$ could have formed aggregates in the aqueous phase. ${ }^{29} \mathrm{C} 1$ and $\mathrm{C} 2$ with

329 highest antioxidant effects had the lowest partitioning percentages in the aqueous phase. Some

330 studies also found that antioxidants with high efficacies have low partitioning coefficients in the

331 aqueous phase in simple $\mathrm{O} / \mathrm{W}$ emulsions. ${ }^{30}$ This study showed that this phenomenon could also

332 happen in complex food systems such as fish oil enriched milk. Contrary to the aqueous phase, C1

333 and $\mathrm{C} 2$ had relatively higher concentration in the precipitate phase than $\mathrm{C} 12$ and $\mathrm{C} 0(P<0.05)$.

334 Based on their antioxidant effects of these compounds, we may hypothesize that the higher

335 partitioning of an antioxidant compound in the precipitate is related to a better antioxidant activity

336 in fish oil enriched milk. Further research on other antioxidant phenolics to test this hypothesis is

337 required. Protein plays an important role in milk as an emulsifier to stabilize the milk fat. The

338 interaction of antioxidant with proteins and particularly those localized in the oil water interface

339 could inhibit the lipid oxidation significantly, which is in agreement with the interfacial concept. ${ }^{31}$

340 The combination of $\mathrm{C} 1$ or $\mathrm{C} 2$ with $\mathrm{C} 12$ seemed to change their relative partitioning behaviors. $\mathrm{C} 12$ 
341 decreased in the oil phase in both combination samples but increased in either the aqueous phase $342(\mathrm{C} 2+\mathrm{C} 12)$ or the precipitate phase $(\mathrm{C} 1+\mathrm{C} 12)(P<0.05)$. Both $\mathrm{C} 1$ and $\mathrm{C} 2$ had a slight decrease in the 343 oil phase and a slightly higher increase in the protein phase in all the combination samples, which 344 could increase the antioxidant effects of the combination and explain the "synergistic" effects 345 observed by the antioxidant study. However, no statistical significances were found. An improved 346 in vivo analysis method to determine the partitioning behavior among the oil, aqueous and the 347 interface phases is required to provide a more clear picture.

Localization of ferulic acid and lipophilized ferulates in fish oil enriched milk and the antioxidant activity mechanism. Apart from the chemical properties of one particular antioxidant, its physical location in an emulsion is also important for its effectiveness. ${ }^{32} \mathrm{C} 0$ was the least 351 effective with regard to lipid oxidation among all the antioxidants tested in this study. As it was 352 reported that milk oil droplets were negatively charged, ${ }^{33}$ this could be caused by the negative charge status of this compound in the milk. Consequently, $\mathrm{C} 0$ could be electrostatically repelled and have relatively lower concentration at the oil droplet surface than uncharged ferulates. In another study, researchers also showed that phenolic compounds with different electrical charge had an impact on their partitioning and the antioxidant activity in salmon oil-in-water emulsions. ${ }^{34}$

357 The difference of effectiveness among antioxidants is also probably due to the different 358 hydrophobicity they have. The hydrophobicity of $\mathrm{C} 12$ is much higher than $\mathrm{C} 1$ or $\mathrm{C} 2$. Antioxidant 359 with high hydrophobicity normally showed better antioxidant activity in $\mathrm{O} / \mathrm{W}$ emulsions. ${ }^{7,31}$ 360 However, antioxidant activity of $\mathrm{C} 1$ or $\mathrm{C} 2$ was significantly higher than $\mathrm{C} 12$ from our observation 361 which could be explained by the cut-off effect. ${ }^{9}$ The critical chain length of a particular esterified 362 phenolic acid differed in different food system. ${ }^{11}$ There were currently three putative hypotheses to explain this cut-off phenomena: the "reduced mobility", the "internalization", and the "self364 aggregation", which was described in detail by Laguerre et al. ${ }^{9}$ Figure 9 explains the assumed 
365 localization of the ferulic acid and lipophilized ferulic acids in fish oil enriched milk based on the 366 theory that lipid oxidation is initiated at the interface, measured lipid oxidation in the different 367 sample codes and the partitioning study and how the combination of antioxidants could influence 368 their localization. From this study, the "internalization" seemed to be the right mechanism to 369 explain our results. $\mathrm{C} 0$ had the highest concentration in the aqueous phase which was showed in 370 Figure 8 and illustrated in Figure 9A. C2 or $\mathrm{C} 1$ had the highest concentration in the precipitate and 371 could have a relatively higher concentration in the interface due to their lower hydrophobicity 372 compared to C12 (Figure 9B). A significant amount of C12 could be internalized inside the oil 373 droplets due to its high hydrophobicity, which was indirectly confirmed by the high percentage of $374 \mathrm{C} 12$ detected in the oil and emulsion fraction (Figure 9C). Partitioning studies in simplified O/W 375 emulsion system with rutin laurate and rutin palmitate showed that very low concentrations were 376 detected in the aqueous phase of the different two or multiple phases systems (buffer / oil phases, 377 buffer / emulsifier phases and emulsion). ${ }^{35}$ This could also support our assumption for the location 378 of $\mathrm{C} 12$ in this study. There is an equilibrium distribution of one particular antioxidant among the oil, 379 interfacial and aqueous phases. It is assumed that the concentration of each compound in the 380 interface decides the antioxidant activity because the oil droplet interface is where the lipid 381 oxidation occurs. ${ }^{36}$ The combination of $\mathrm{C} 12$ with $\mathrm{C} 1$ or $\mathrm{C} 2$ could disturb the equilibrium 382 distribution of $\mathrm{C} 1$ or $\mathrm{C} 2$ between the oil and interface as also observed in other studies between 383 tocopherol and caffeates in model emulsions. ${ }^{37}$ The combination of $\mathrm{C} 1$ or $\mathrm{C} 2$ with $\mathrm{C} 12$ could lead 384 to a relatively higher concentration of $\mathrm{C} 1$ or $\mathrm{C} 2$ in the interface than when $\mathrm{C} 1$ or $\mathrm{C} 2$ was added in 385 the fish oil enriched milk emulsion alone (Figure 9D). The higher concentration of $\mathrm{C} 1$ or $\mathrm{C} 2$ at the 386 interface can lead to better antioxidant effects, which could explain the indication of the 387 "synergistic" antioxidant effect observed in this study. In another study, Panya et al. ${ }^{36}$ showed that 388 the equilibrium distribution of antioxidant compound in the oil, interface and aqueous phase could 
389 be broken by adding a surfactant Tween-20 and the antioxidant activity was changed accordingly in 390 O/W emulsions. The present study demonstrated that antioxidant-antioxidant interaction could 391 influence their antioxidant activity in fish oil enriched milk, which could also be related to the 392 change of partitioning coefficients of the antioxidants at the interface. The mechanism of this kind 393 of interaction is still not clear. Challenges include the quantification of distribution of antioxidant 394 compounds in the oil, interfacial, and aqueous phases in vivo in a complicated food system like fish 395 oil enriched milk emulsion. In addition, there are also various compounds in a food system that 396 could influence the partitioning of antioxidant in the interface. More research is needed to study the 397 particular factors that could influence the localization of antioxidants and further clarify the 398 “internalization” or "localization" mechanism.

Although partitioning of an antioxidant in the interface of an emulsion system is relevant for its antioxidant activity in inhibiting lipid oxidation, this could not apply to the protein oxidation. Lipid oxidation could originate from the interface and generate primary and secondary lipid oxidation products that react with protein and cause the induction of protein oxidation. An antioxidant such as $\mathrm{C} 1$ or $\mathrm{C} 2$ that localizes at the interface may inhibit lipid oxidation efficiently and thus protein oxidation. However, antioxidant like $\mathrm{C} 0$ which has high concentration in aqueous phase and consequently less efficient lipid oxidation activity could still inhibit protein oxidation. Further research on how $\mathrm{C} 0$ could retard the reaction between lipid oxidation products and proteins would help to explain the mechanism.

\section{Funding}

The financial support provided by China Scholarship Council (No. 201608350049) for Xujian Qiu's visit to DTU Food is acknowledged.

\section{Notes}


412 The authors declare no competing financial interest.

\section{ACKNOWLEDGEMENTS}

414 We thank Maritex (subsidiary of TINE BA, Norway) for providing the fish oil to our research. 


\section{REFERENCES}

416 (1) Calder, P. C. n-3 Fatty acids and cardiovascular disease: evidence explained and mechanisms 417 explored. Clin. Sci. 2004, 107 (1), 1-11.

(2) Calder, P. C. N-3 Fatty Acids, Inflammation and Immunity: New Mechanisms To Explain Old Actions. Proc. Nutr. Soc. 2013, 72 (3), 326-336.

(3) Frankel, E. N. N. Lipid Oxidation. Prog. Lipid Res. 1980, 19 (1-2), 488.

(4) Let, M. B.; Jacobsen, C.; Frankel, E. N.; Meyer, A. S. Oxidative flavour deterioration of fish oil enriched milk. Eur. J. Lipid Sci. Technol. 2003, 105 (9), 518-528.

(5) Jacobsen, C.; Sørensen, A. -D.M.; Nielsen, N. S. Stabilization of omega-3 oils and enriched 424 foods using antioxidants. In Food Enrichment with Omega-3 Fatty Acids; Jacobsen, C., Nielsen, N. S., Horn, A.F., Sørensen, A. -D.M., Eds.; Woodhead Publishing Limited: Cambridge, UK, 2013; pp $426 \quad 130-149$.

(6) Porter, W. L. Recent Trends in Food Applications of Antioxidants. In Autoxidation in Food and Biological Systems; Simic, M. G., Karel, M., Eds.; Springer US: Boston, MA, 1980; pp 295-365. emulsions: contrast in relative effectiveness of antioxidants in bulk versus dispersed systems. $J$.

431 Agric. Food Chem. 1989, 37 (3), 615-624. 
(9) Laguerre, M.; Sørensen, A.-D. M.; Bayrasy, C.; Lecomte, J.; Jacobsen, C.; Decker, E. A.; Villeneuve, P. Role of hydrophobicity on antioxidant activity in lipid dispersions, From the polar paradox to the cut-off theory. In Lipid Oxidation:Challenges in Food Systems; Logan A., Nienaber U., Pan X., Eds.; AOCS Press: Urbana, IL, 2013; pp 261-295.

(10) Costa, M.; Losada-Barreiro, S.; Paiva-Martins, F.; Bravo-Diaz, C. Optimizing the efficiency of antioxidants in emulsions by lipophilization: tuning interfacial concentrations. $R S C A d v$. 2016, 6 (94), 91483-91493.

(11) Alemán, M.; Bou, R.; Guardiola, F.; Durand, E.; Villeneuve, P.; Jacobsen, C.; Sørensen, A. -D. M. Antioxidative effect of lipophilized caffeic acid in fish oil enriched mayonnaise and milk. Food Chem. 2015, 167, 236-244.

(12) Sørensen, A.-D. M.; Petersen, L. K.; de Diego, S.; Nielsen, N. S.; Lue, B.-M.; Yang, Z.; Xu, X.; Jacobsen, C. The antioxidative effect of lipophilized rutin and dihydrocaffeic acid in fish oil enriched milk. Eur. J. Lipid Sci. Technol. 2012, 114 (4), 434-445.

(13) Sørensen, A.-D. M.; Lyneborg, K. S.; Villeneuve, P.; Jacobsen, C. Alkyl chain length impacts the antioxidative effect of lipophilized ferulic acid in fish oil enriched milk. J. Funct. Foods 2015, 18, Part B, 959-967.

(14) Sørensen, A.-D. M.; Durand, E.; Laguerre, M.; Bayrasy, C.; Lecomte, J.; Villeneuve, P.; Jacobsen, C. Antioxidant Properties and Efficacies of Synthesized Alkyl Caffeates, Ferulates, and Coumarates. J. Agric. Food Chem. 2014, 62 (52), 12553-12562.

(15) Let, M. B.; Jacobsen, C.; Sørensen, A.-D. M.; Meyer, A. S. Homogenization Conditions Affect the Oxidative Stability of Fish Oil Enriched Milk Emulsions: Lipid Oxidation. J. Agric. Food Chem. 2007, 55 (5), 1773-1780. 
457 (16) Bligh, E. G.; Dyer, W. J. A rapid method of total lipid extraction and purification. Can. J. 458 Biochem. Physiol. 1959, 37 (8), 911-917.

459 (17) Shantha, N. C.; Decker, E. A. Rapid, sensitive, iron-based spectrophotometric methods for 460 determination of peroxide values of food lipids. J. AOAC Int. 1994, 77 (2), 421-424.

461 (18) AOCS Official Method Ce 1b-89. Fatty Acid Composition by GC. Marine Oils. AOCS, 462 Champaign, IL, 1998.

463 (19) AOCS Official Method Ce 8-89. Determination of tocopherols and tocotrienols in vegetable 464 oils and fats by HPLC. AOCS, Champaign, IL, 1997.

465 (20) Levine, R. L.; Garland, D.; Oliver, C. N.; Amici, A.; Climent, I.; Lenz, A. G.; Ahn, B. W.;

466 Shaltiel, S.; Stadtman, E. R. Determination of carbonyl content in oxidatively modified proteins. 467 Methods Enzymol. 1990, 186, 464-478.

468 (21) Fenaille, F.; Parisod, V.; Visani, P.; Populaire, S.; Tabet, J. C.; Guy, P. A. Modifications of 469 milk constituents during processing: A preliminary benchmarking study. Int. Dairy J. 2006, 16 (7), $470 \quad 728-739$.

471 (22) Jacobsen, C.; Meyer, A. S.; Adler-Nissen, J. Oxidation mechanisms in real food emulsions: 472 method for separation of mayonnaise by ultracentrifugation. J. Food Lipids 1998, 5 (2), 87-101.

473 (23) Guyot, B.; Gueule, D.; Pina, M.; Farines, V.; Farines, M. Enzymatic synthesis of fatty esters in 474 5-caffeoyl quinic acid. Eur. J. Lipid Sci. Technol. 2000, 93-96.

475 (24) Sørensen, A. -D. M.; Baron, C. P.; Let, M. B.; Brüggemann, D. A.; Pedersen, L. R. L.; 476 Jacobsen, C. Homogenization conditions affect the oxidative stability of fish oil enriched milk 
477 emulsions: Oxidation linked to changes in protein composition at the oil-water interface. J. Agric.

478 Food Chem. 2007, 55 (5), 1781-1789.

479 (25) Venkateshwarlu, G.; Let, M. B.; Meyer, A. S.; Jacobsen, C. Chemical and Olfactometric 480 Characterization of Volatile Flavor Compounds in a Fish Oil Enriched Milk Emulsion. J. Agric.

481 Food Chem. 2004, 52 (2), 311-317.

482 483

484 485 486

487 488 489

490

491 492

493

494 495 496

497 498

(26) Olsen, E.; Vogt, G.; Saarem, K.; Greibrokk, T.; Nilsson, A. Autoxidation of cod liver oil with tocopherol and ascorbyl palmitate. J. Am. Oil Chem. Soc. 2005, 82 (2), 97-103.

(27) Soyer, A.; Özalp, B.; Dalmış, Ü.; Bilgin, V. Effects of freezing temperature and duration of frozen storage on lipid and protein oxidation in chicken meat. Food Chem. 2010, 120 (4), 10251030.

(28) Heinecke, J. W.; Li, W.; Daehnke, H. L.; Goldstein, J. A. Dityrosine, a specific marker of oxidation, is synthesized by the myeloperoxidase-hydrogen peroxide system of human neutrophils and macrophages. J. Biol. Chem. 1993, 268 (6), 4069-4077.

(29) Laguerre, M.; Bayrasy, C.; Lecomte, J.; Chabi, B.; Decker, E. A.; Wrutniak-Cabello, C.;

Cabello, G.; Villeneuve, P. How to boost antioxidants by lipophilization? Biochimie. 2013, 95(1): $20-26$.

(30) Laguerre, M.; López Giraldo, L. J.; Lecomte, J.; Figueroa-Espinoza, M.-C.; Baréa, B.; Weiss, J.; Decker, E. A.; Villeneuve, P. Chain Length Affects Antioxidant Properties of Chlorogenate Esters in Emulsion: The Cutoff Theory Behind the Polar Paradox. J. Agric. Food Chem. 2009, 57 (23), 11335-11342.

(31) Frankel, E. N.; Huang, S.-W.; Kanner, J.; German, J. B. Interfacial phenomena in the evaluation of antioxidants: bulk Oils vs emulsions. J. Agric. Food Chem. 1994, 42 (5), 1054-1059. 
499 (32) McClements, D.J.; Decker, E.A. Lipid oxidation in oil-in-water emulsions: impact of 500 molecular environment on chemical reactions in heterogeneous food systems. J. Food Sci. 2000, 65 $501(8), 1270-1282$.

502 (33) Ménard, O.; Ahmad, S.; Rousseau, F.; Briard-Bion, V.; Gaucheron, F.; Lopez, C. Buffalo vs. 503 cow milk fat globules: size distribution, zeta-potential, compositions in total fatty acids and in polar 504 lipids from the milk fat globule membrane. Food Chem. 2010, 120 (2), 544-551.

505

506

507 508 509
(34) Mei, L.; McClements, D. J.; Decker, E. A. Lipid oxidation in emulsions as affected by charge status of antioxidants and emulsion droplets. J. Agric. Food Chem. 1999, 47 (6), 2267-2273.

(35) Lue, B.-M.; Sørensen, A.-D. M.; Jacobsen, C.; Guo, Z.; Xu, X. Antioxidant efficacies of rutin and rutin esters in bulk oil and oil-in-water emulsion. Eur. J. Lipid Sci. Technol. 2016, 119(4), 115.

(36) Panya, A.; Laguerre, M.; Bayrasy, C.; Lecomte, J.; Villeneuve, P.; McClements, D. J.; Decker, E. A. An Investigation of the Versatile Antioxidant Mechanisms of Action of Rosmarinate Alkyl Esters in Oil-in-Water Emulsions. J. Agric. Food Chem. 2012, 60 (10), 2692-2700.

(37) Sørensen, A.-D. M.; Villeneuve, P.; Jacobsen, C. Alkyl caffeates as antioxidants in O/W emulsions: Impact of emulsifier type and endogenous tocopherols. Eur. J. Lipid Sci. Technol. 2017, $119(6), \mathrm{e} 201600276$.

(6)

.




\section{Figure captions:}

521 Figure 1. Changes of PV in fish oil enriched milk samples with ferulic acid and different 522 lipophilized ferulates during 13 days storage at $5{ }^{\circ} \mathrm{C}$. Data points and error bars represent means \pm 523 standard deviations $(\mathrm{n}=2)$. Con, control; $\mathrm{C}$, ferulic acid; $\mathrm{C}$ 1, methyl ferulate; $\mathrm{C} 2$, ethyl ferulate; 524 C12, dodecyl ferulate.

525

526

527

528

530

531

532

533

534

535

536

537

538

539

540
Figure 2. Change of hexanal in fish oil enriched milk samples with ferulic acid and different lipophilized ferulates during 13 days storage at $5{ }^{\circ} \mathrm{C}$. Data points and error bars represent means \pm standard deviations $(\mathrm{n}=3)$. Con, control; $\mathrm{C} 0$, ferulic acid; $\mathrm{C} 1$, methyl ferulate; $\mathrm{C} 2$, ethyl ferulate; C12, dodecyl ferulate.

Figure 3. Change of 1-penten-3-one in fish oil enriched milk samples with ferulic acid and different lipophilized ferulates during 13 days storage at $5{ }^{\circ} \mathrm{C}$. Data points and error bars represent means \pm standard deviations $(n=3)$. Con, control; C0, ferulic acid; $\mathrm{C} 1$, methyl ferulate; $\mathrm{C} 2$, ethyl ferulate; C12, dodecyl ferulate.

Figure 4. Change of 1-penten-3-ol in fish oil enriched milk samples with ferulic acid and different lipophilized ferulates during 13 days storage at $5{ }^{\circ} \mathrm{C}$. Data points and error bars represent means \pm standard deviations $(\mathrm{n}=3)$. Con, control; $\mathrm{C}$, ferulic acid; $\mathrm{C} 1$, methyl ferulate; $\mathrm{C} 2$, ethyl ferulate; C12, dodecyl ferulate.

Figure 5. Change of 2,4-hepatadienal in fish oil enriched milk samples with ferulic acid and different lipophilized ferulates during 13 days storage at $5{ }^{\circ} \mathrm{C}$. Data points and error bars represent means \pm standard deviations $(\mathrm{n}=3)$. Con, control; $\mathrm{C} 0$, ferulic acid; $\mathrm{C} 1$, methyl ferulate; $\mathrm{C} 2$, ethyl ferulate; C12, dodecyl ferulate. 
542 Figure 6. Changes of a- tocopherol in fish oil enriched milk samples with ferulic acid and different 543 lipophilized ferulates during 13 days storage at $5^{\circ}$ C. Data points and error bars represent means $544 \pm$ standard deviations ( $\mathrm{n}=2$ ). Con, control; $\mathrm{C}$, ferulic acid; $\mathrm{C} 1$, methyl ferulate; $\mathrm{C} 2$, ethyl ferulate; 545 C12, dodecyl ferulate.

546 Figure 7. Changes of carbonyl content in fish oil enriched milk samples with ferulic acid and 547 different lipophilized ferulates during 13 days storage at $5{ }^{\circ} \mathrm{C}$. Data points and error bars represent 548 means \pm standard deviations $(\mathrm{n}=3$ ). Con, control; $\mathrm{C} 0$, ferulic acid; $\mathrm{C} 1$, methyl ferulate; $\mathrm{C} 2$, ethyl 549 ferulate; C12, dodecyl ferulate.

550 Figure 8. Partitioning of ferulic acid and lipophilized ferulates into 3 different phases in the milk 551 samples: Oil and emulsion, aqueous and precipitate. Data points and error bars represent means \pm 552 standard deviations ( $\mathrm{n}=3$ ). $\mathrm{C}$, ferulic acid; $\mathrm{C}$, methyl ferulate; $\mathrm{C} 2$, ethyl ferulate; C12, dodecyl 553 ferulate.

554 Figure 9. A schematic illustration of assumed localization and interaction of ferulic acid and 555 different lipophilized ferulates in fish oil enriched milk: (A) ferulic acid is mainly localized at the 556 aqueous phase; (B) ferulates with short alkyl chain lengths such as methyl ferulate and ethyl 557 ferulate have high concentration at the interface; (C) Feurates with medium alkyl chain lengths are 558 highly hydrophobic and are mainly in the oil; (D) Interaction between ferulates with short and 559 medium alkyl chain lengths can change the equilibrium distribution of ferulates with short alkyl 560 chain length and increase its concentration at the interface. 


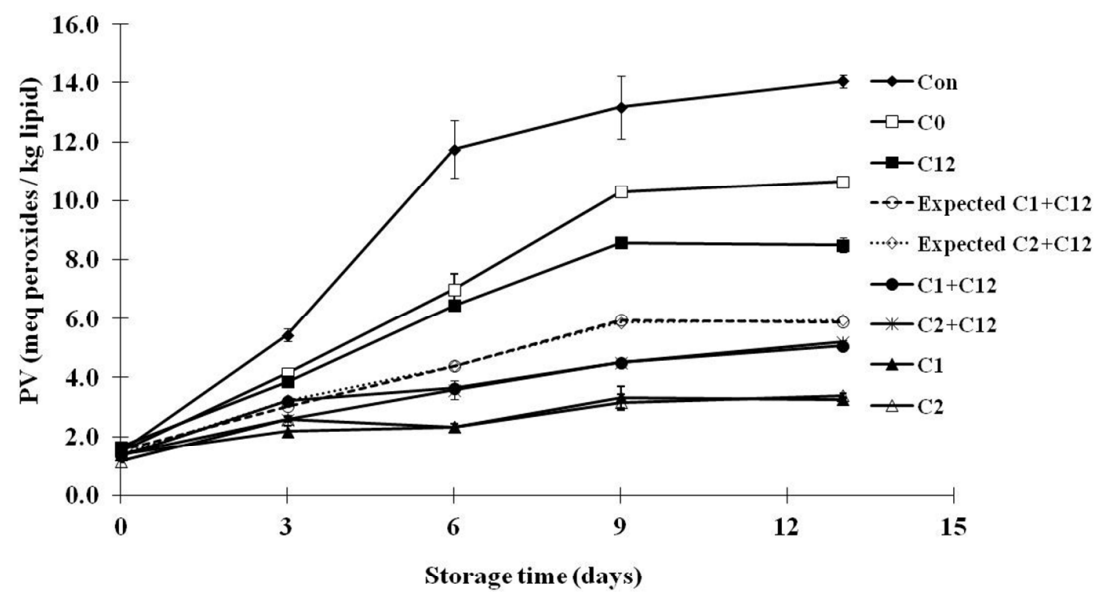

Figure 1

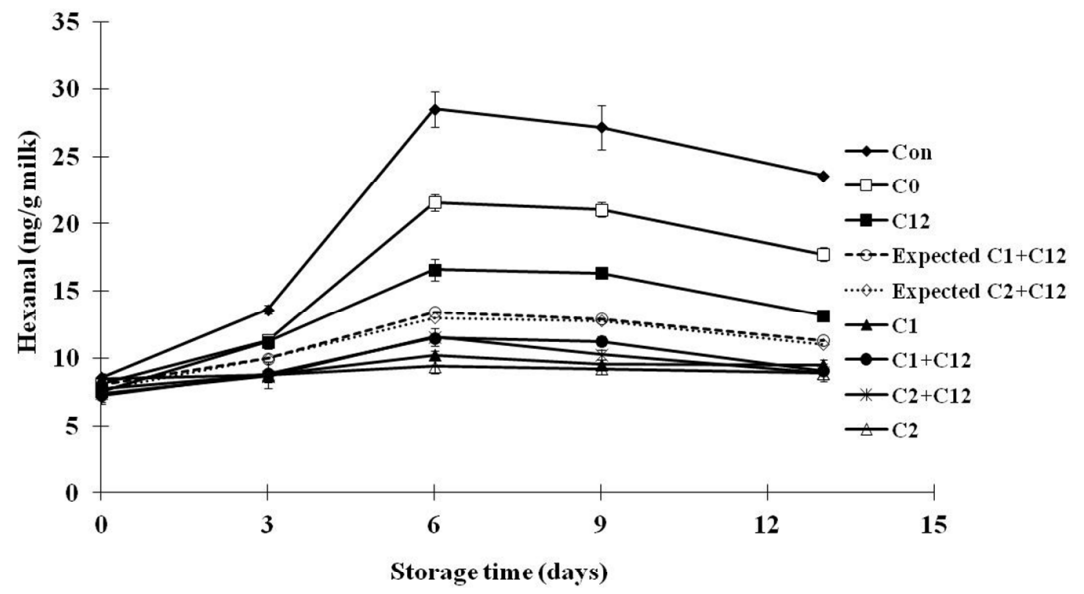

Figure 2 


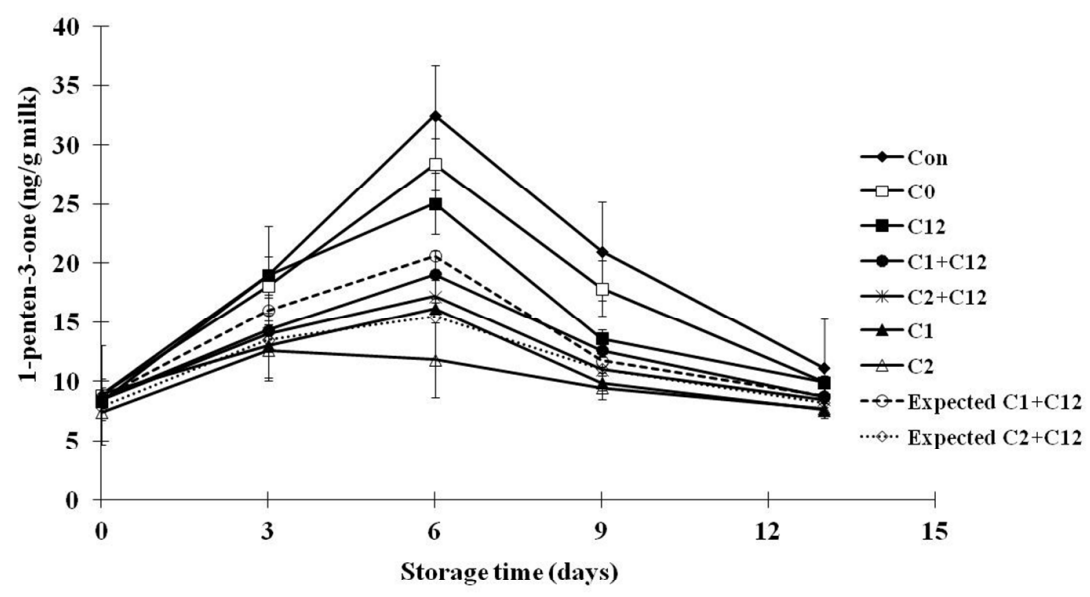

Figure 3

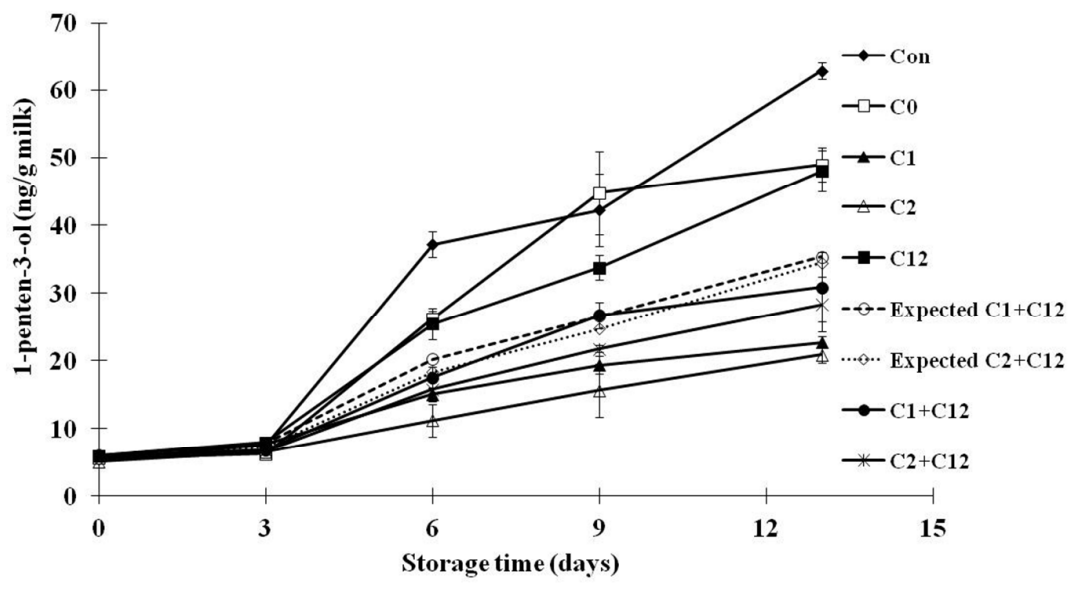

Figure 4 


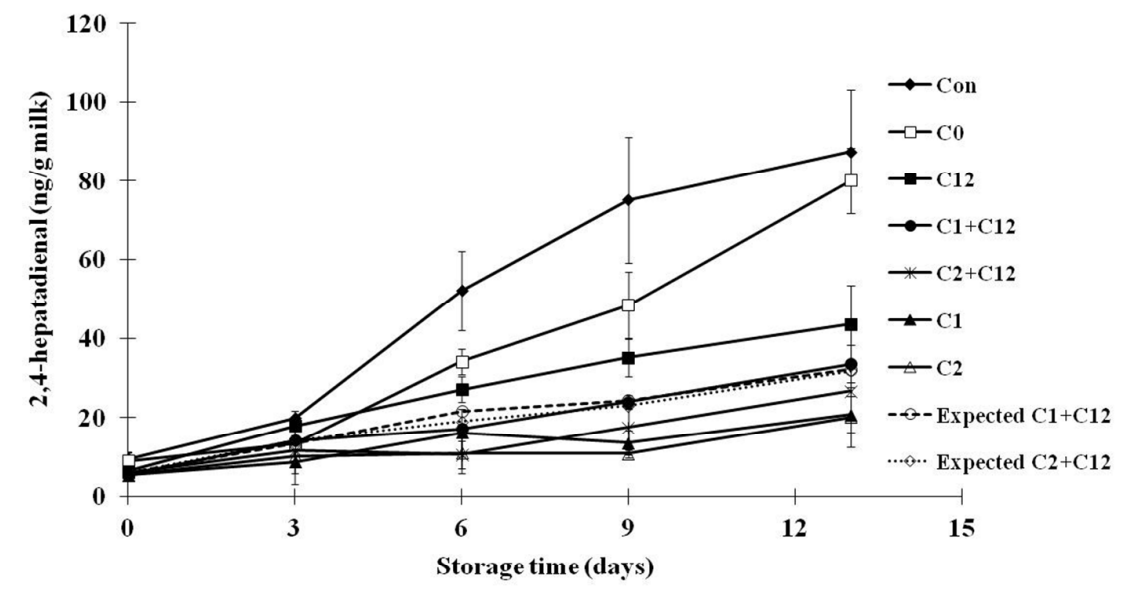

Figure 5

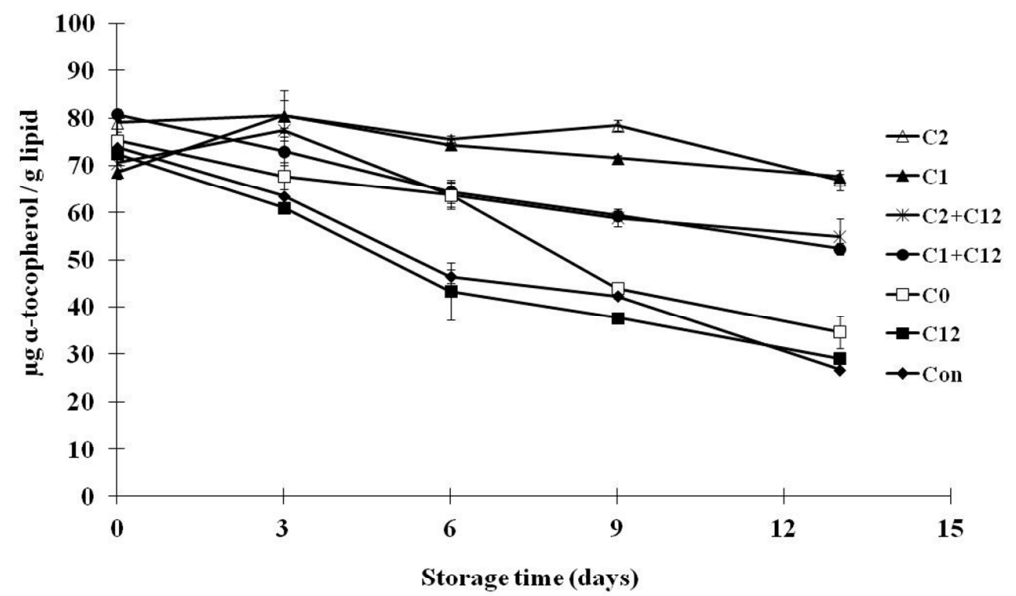

Figure 6 


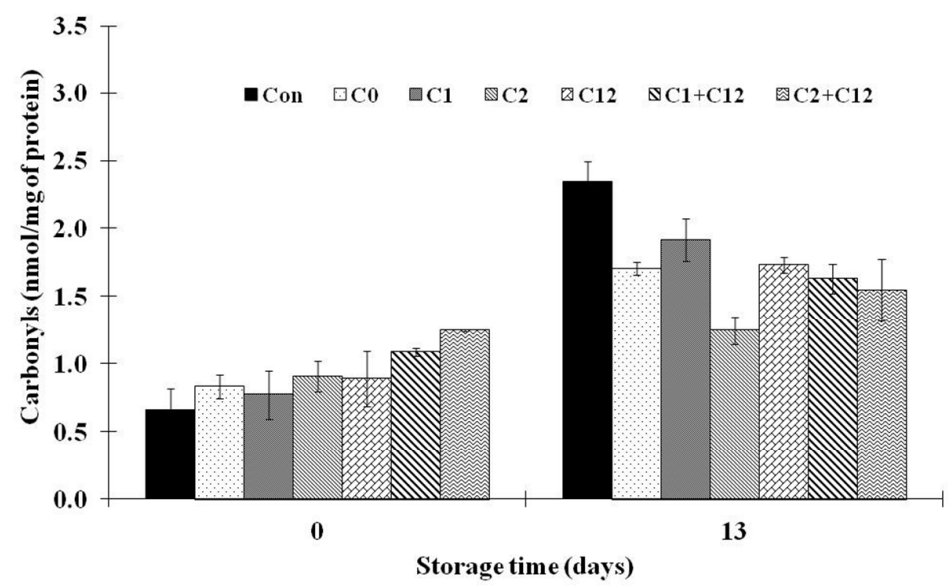

Figure 7
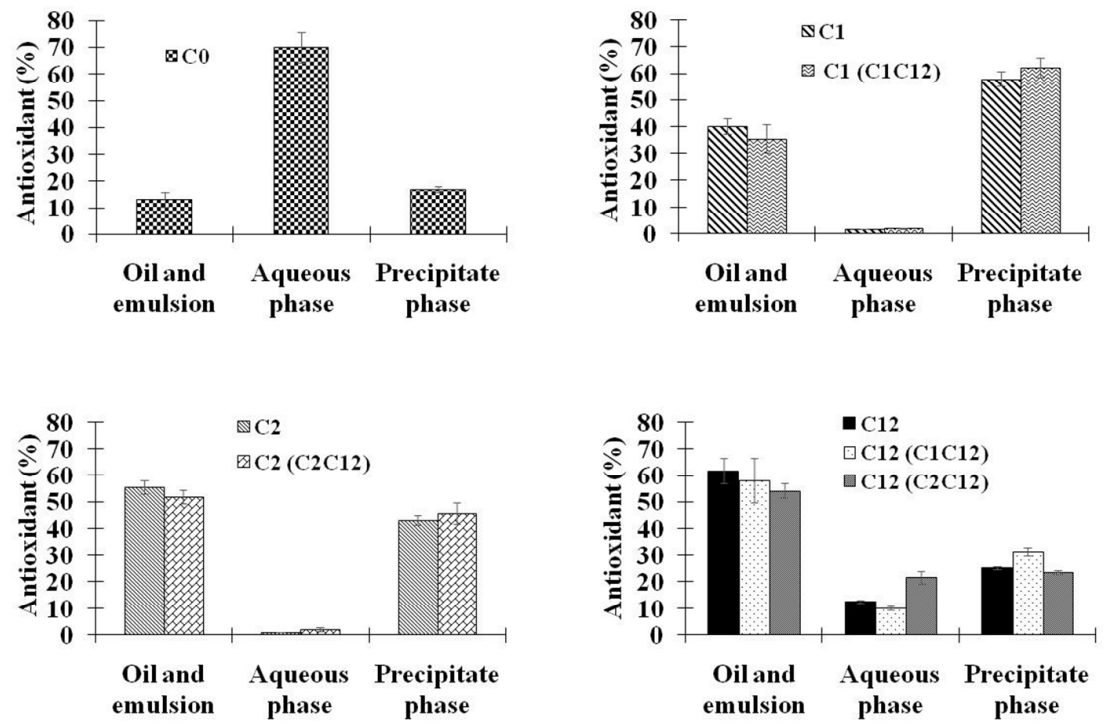

Figure 8 

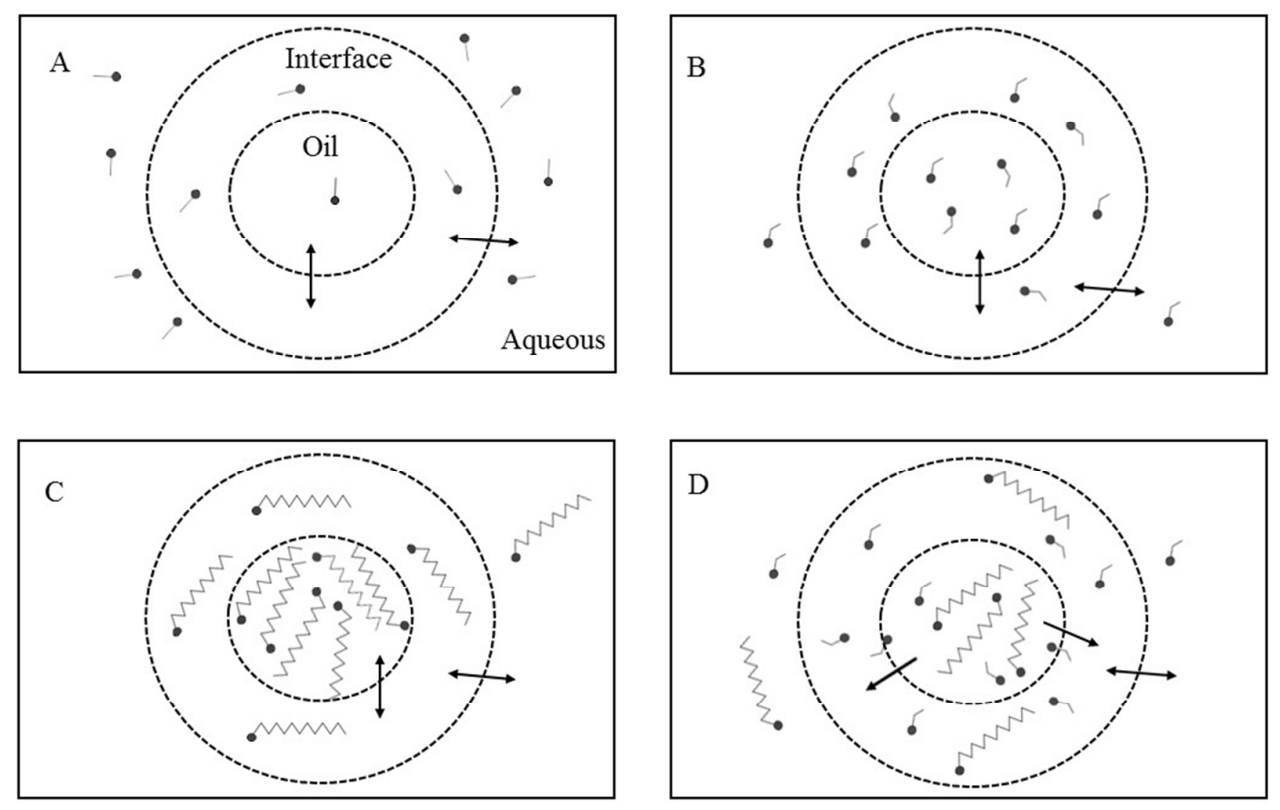

Figure 9 
Graphic for table of contents

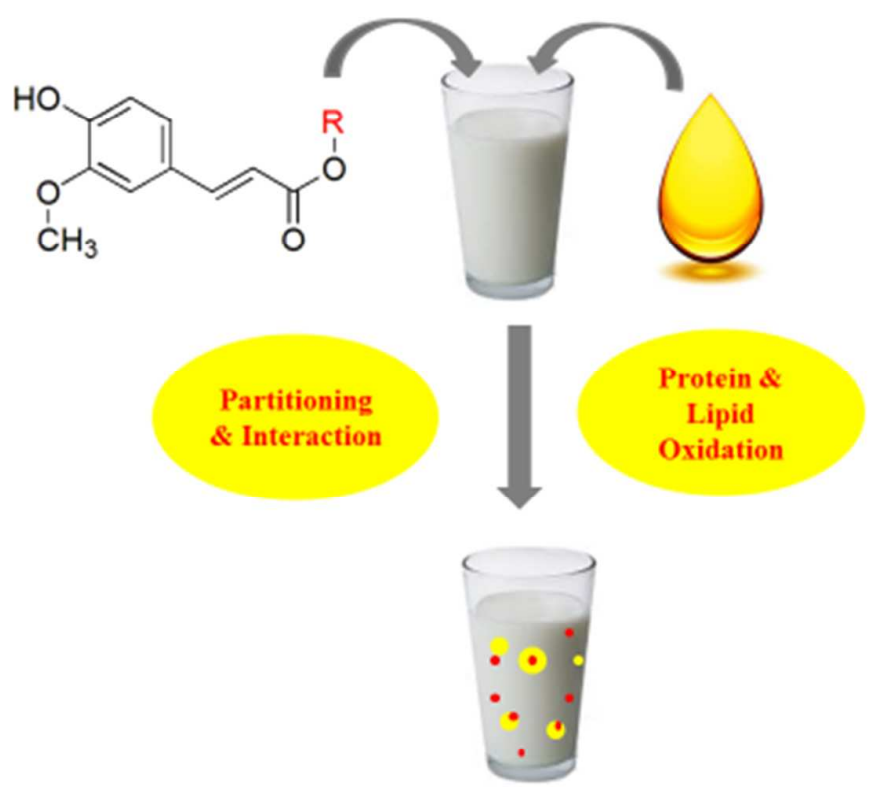




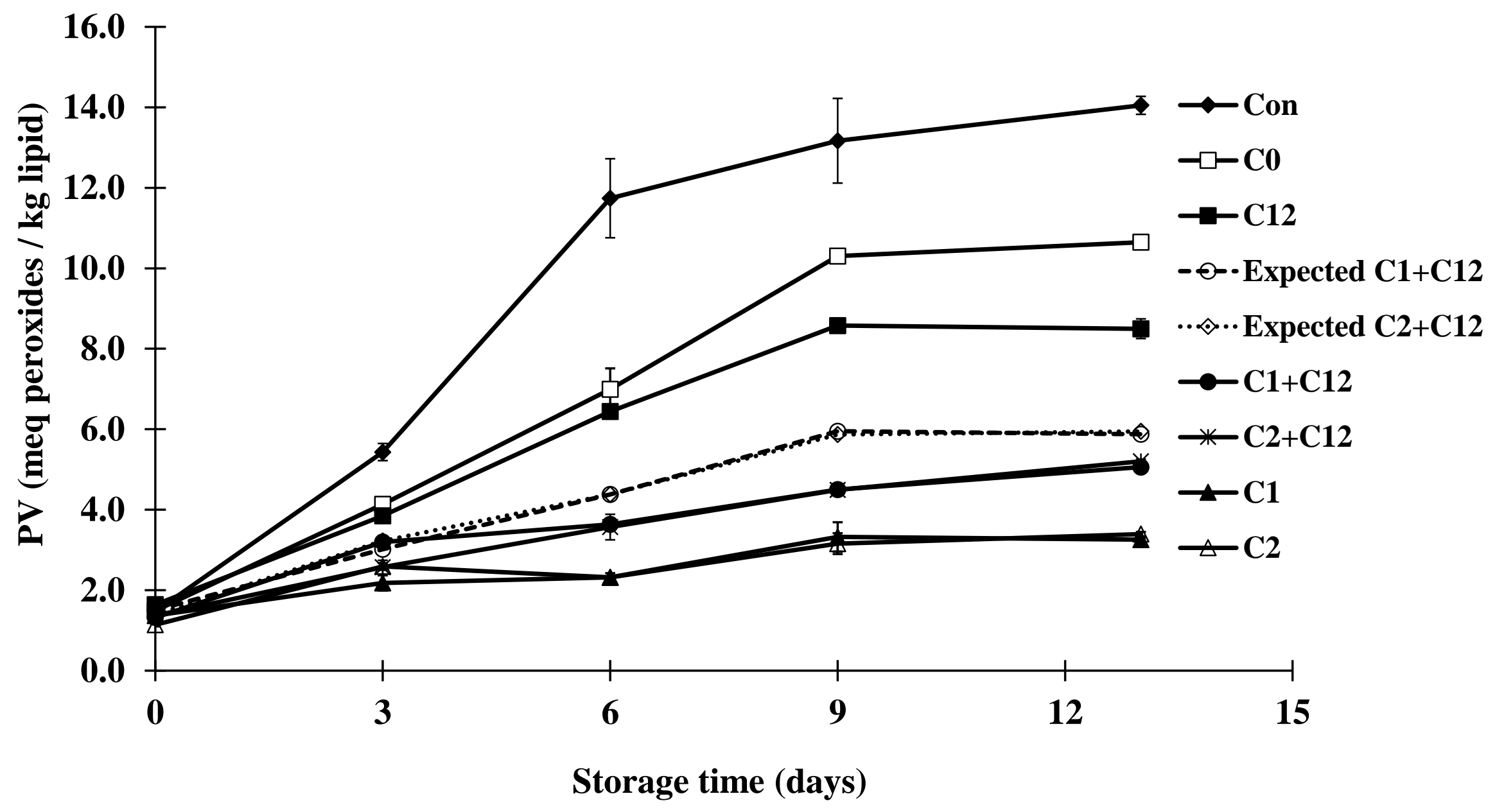




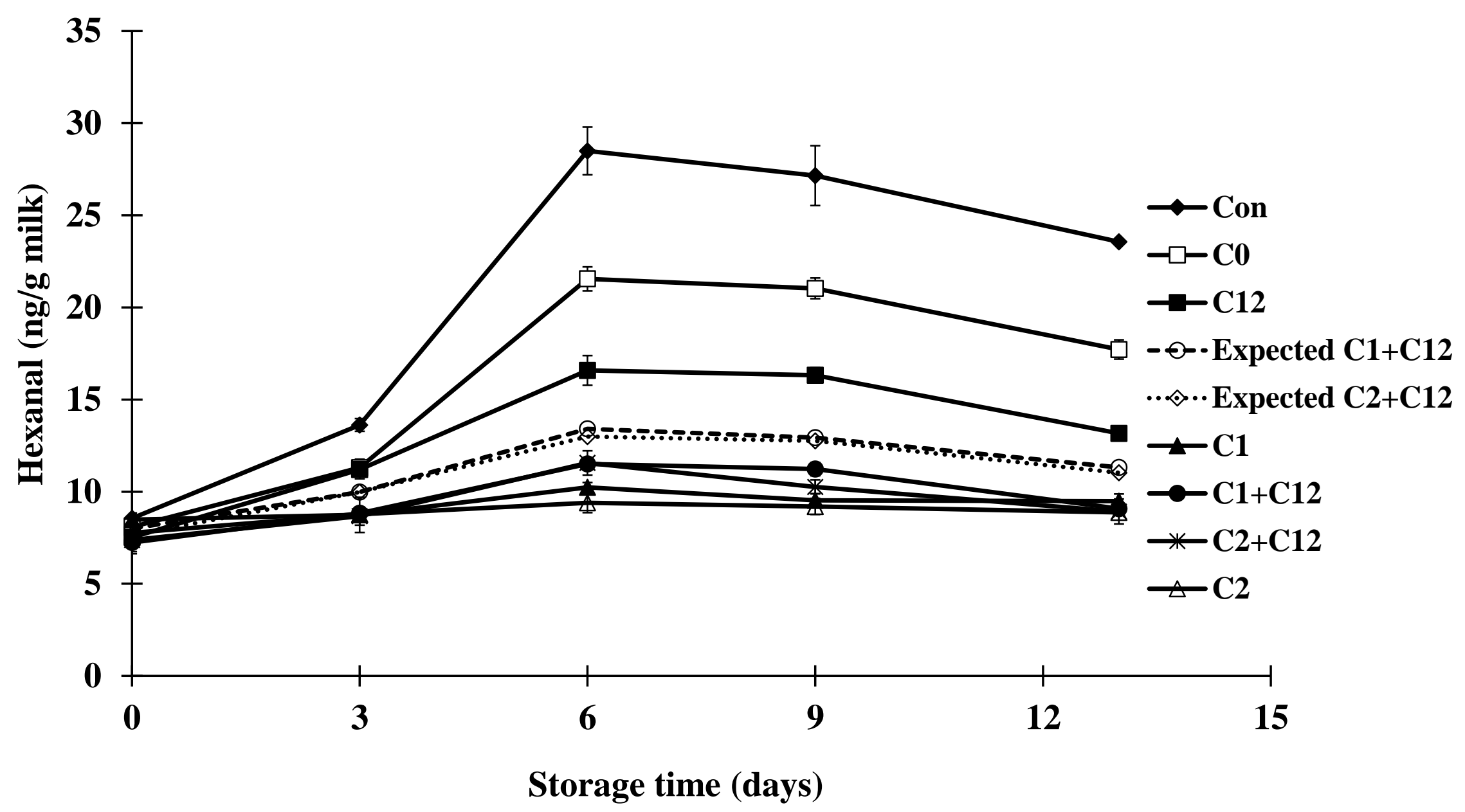




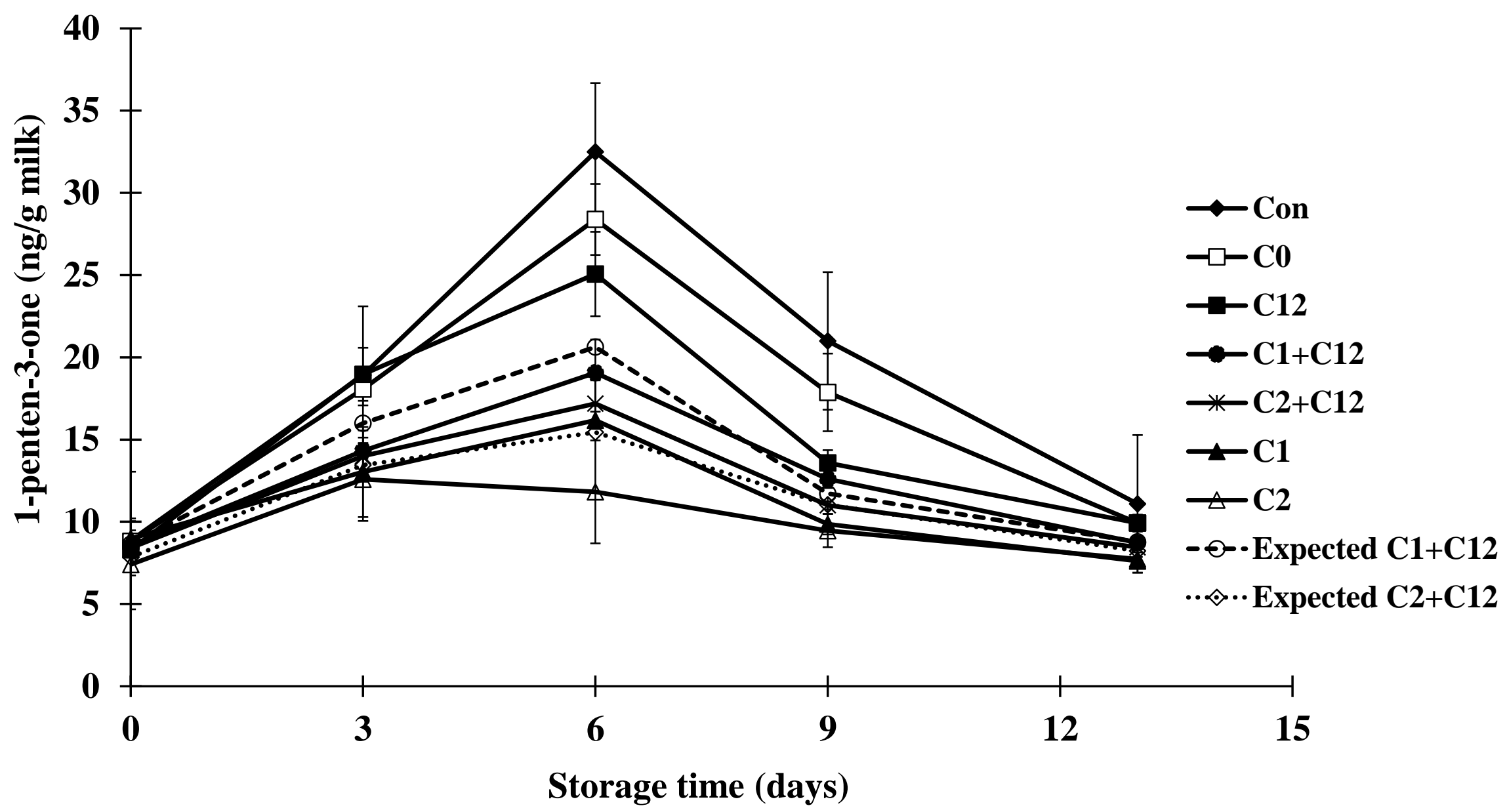




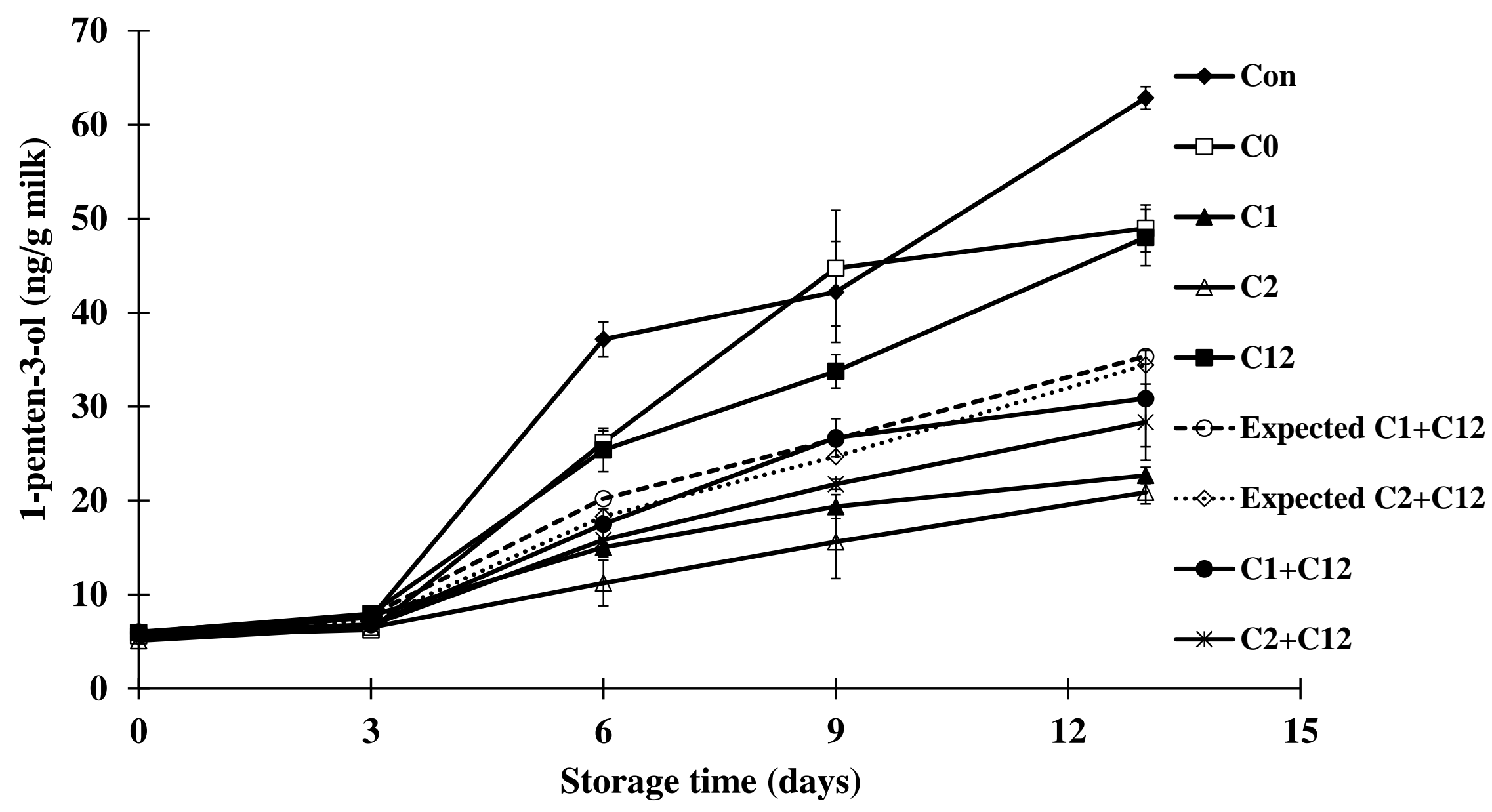




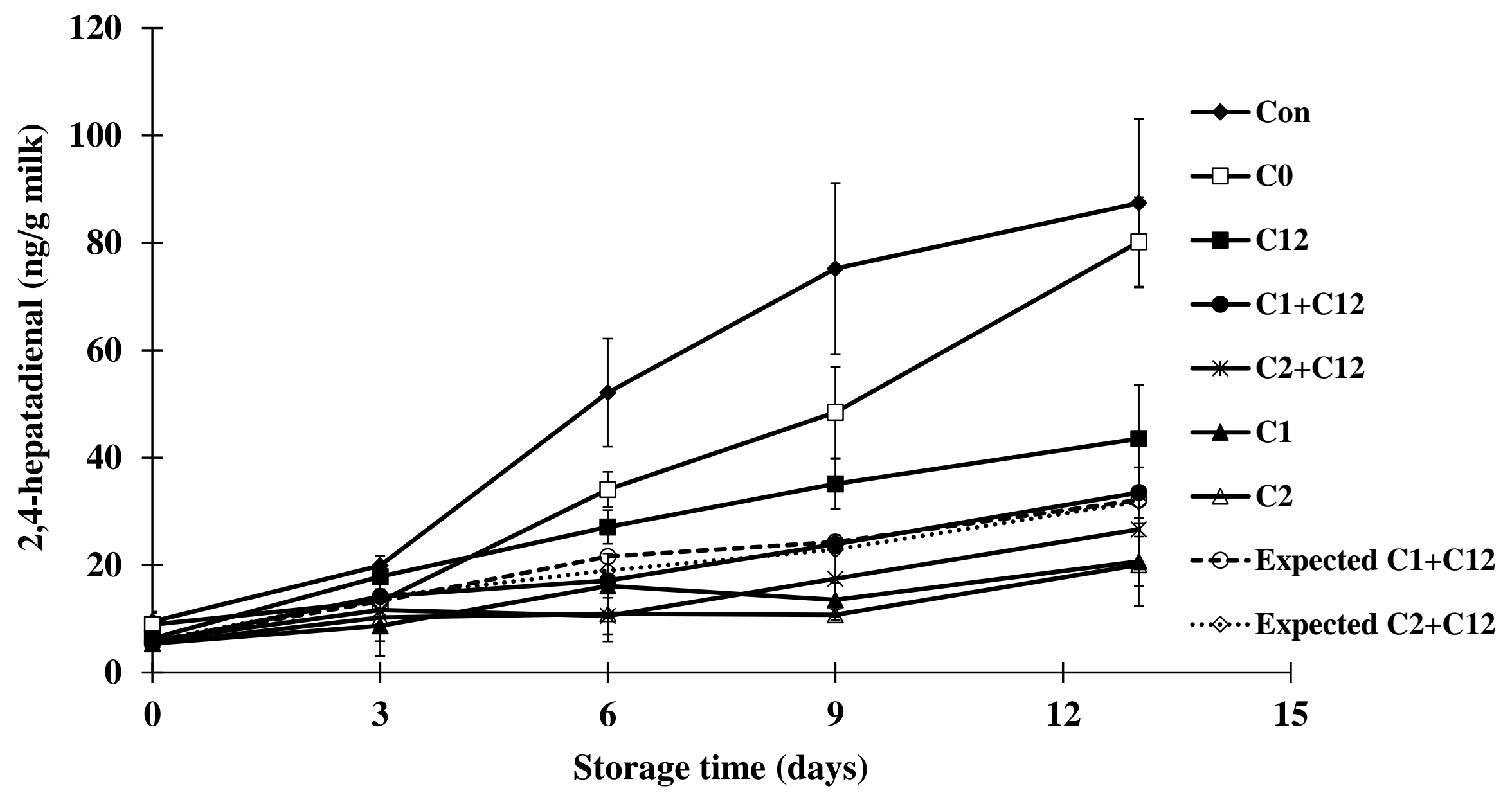




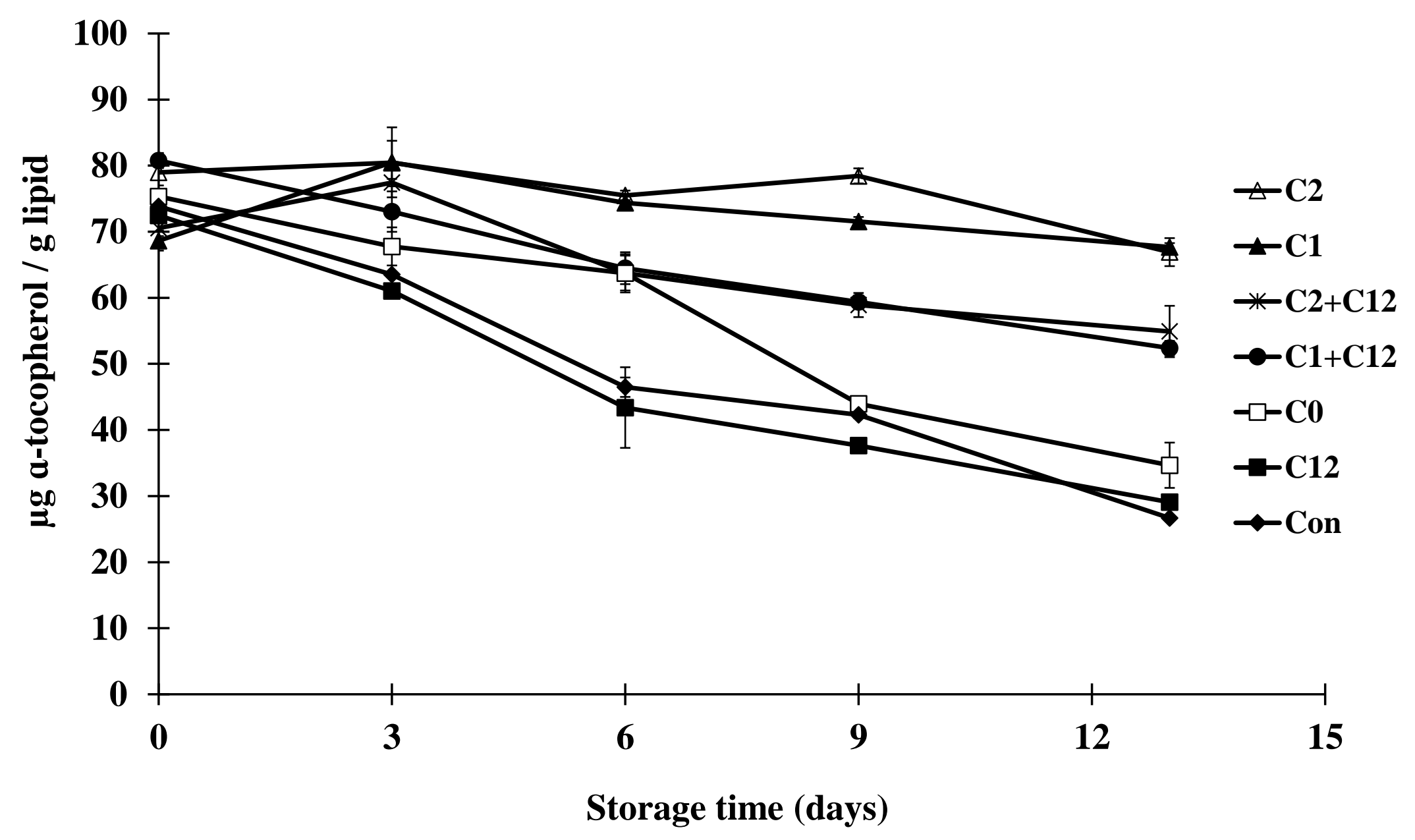




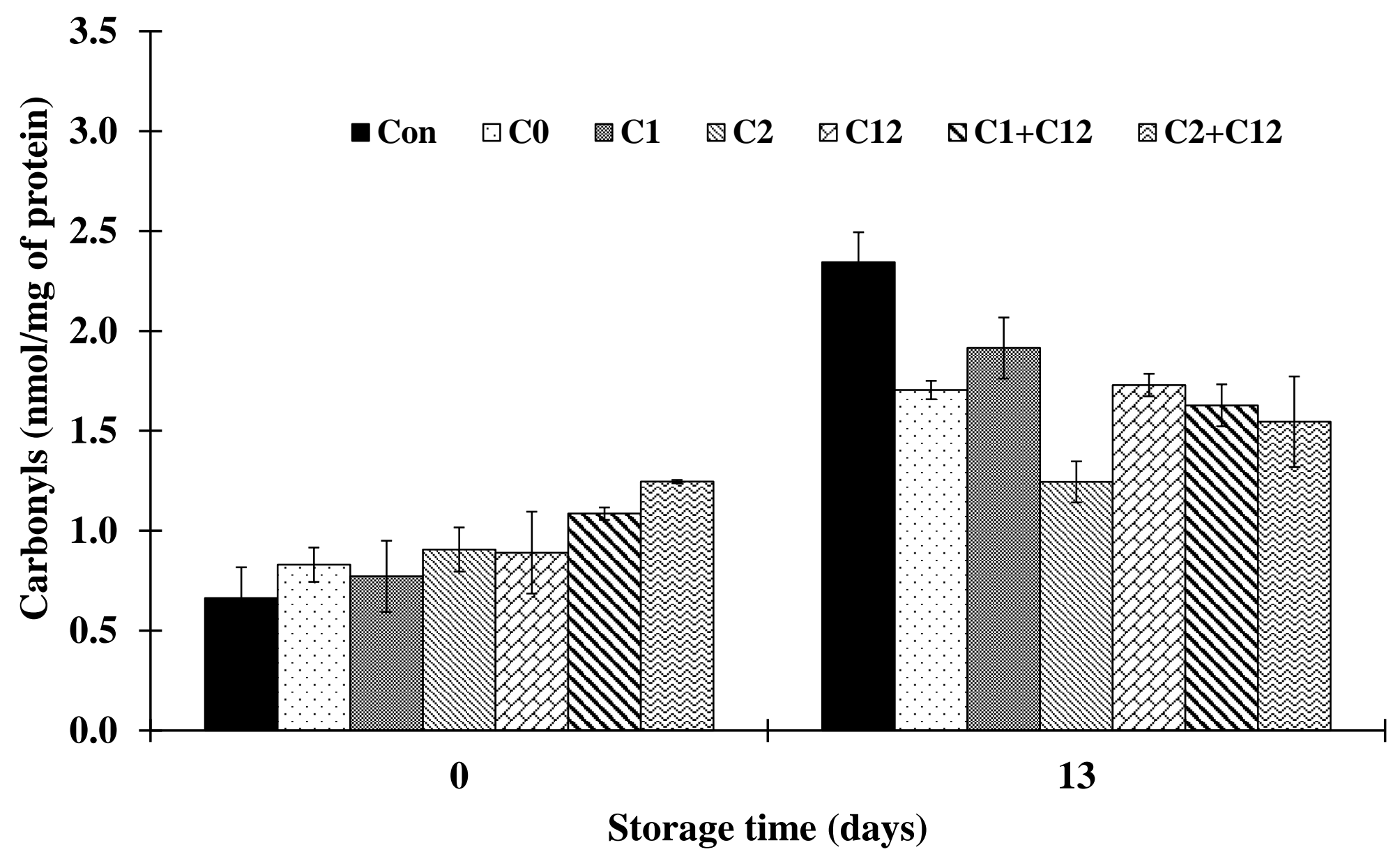



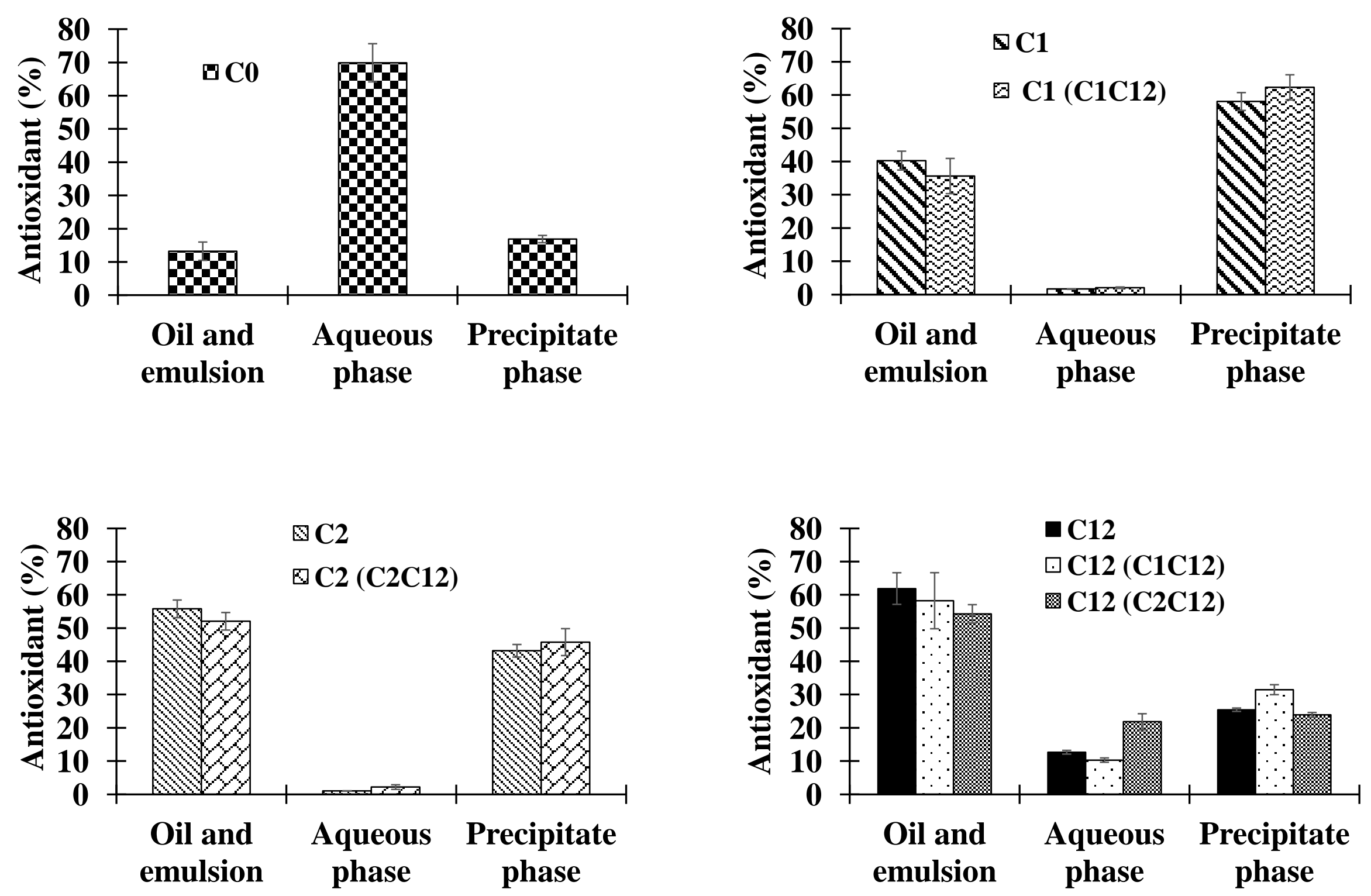


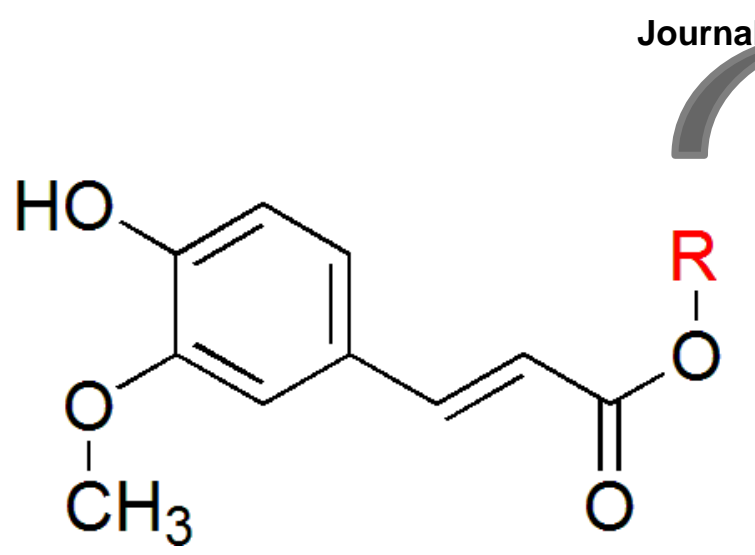

\section{Partitioning \& Interaction

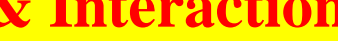

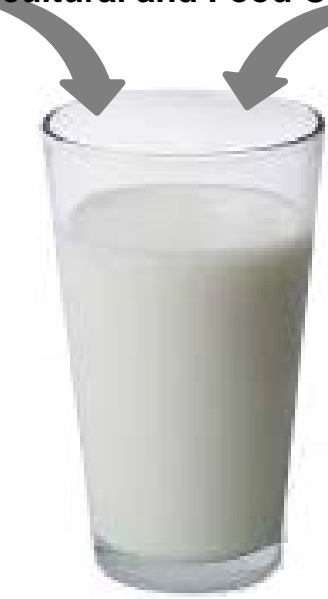

Page 42 of 42

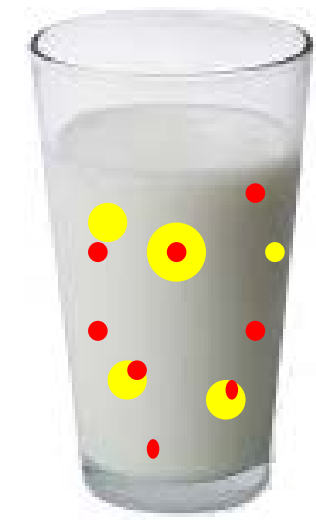

Protein \& Lipid Oxidation 